\title{
Substituent Effects on the Patterns of Intermolecular Interactions of 3-Alkyl and 3-Cycloalkyl Derivatives of Phenytoin: A Crystallographic and Quantum-Chemical Study
}

\author{
Nemanja Trišović, ${ }^{* \dagger \odot}$ Lidija Radovanović, ${ }^{\ddagger}$ Goran V. Janjićc, Stefan T. Jelić, ${ }^{\S}$ and Jelena Rogan ${ }^{\dagger}$ \\ ${ }^{\dagger}$ Faculty of Technology and Metallurgy, University of Belgrade, Karnegijeva 4, 11000 Belgrade, Serbia \\ ${ }^{\ddagger}$ Innovation Center, Faculty of Technology and Metallurgy, University of Belgrade, Karnegijeva 4, 11000 Belgrade, Serbia \\ ${ }^{\S}$ Institute of Chemistry, Technology and Metallurgy, University of Belgrade, Njegoševa 12, 11000 Belgrade, Serbia \\ "Institute for Multidisciplinary Research, University of Belgrade, Kneza Višeslava 1, 11000 Belgrade, Serbia
}

Supporting Information

\begin{abstract}
A series of five derivatives of the anticonvulsant drug phenytoin was synthesized, and their crystal structures were determined. The relationship between the molecular and crystal structure of the investigated compounds was rationalized in the context of contribution of intermolecular interactions and supramolecular structural motifs. The conformational preferences were analyzed by comparing the rotational freedom of the phenyl groups in the investigated compounds with 5,5-diphenylhydantoins from the Cambridge Structural Database. With the exception of compound 3 bearing the cyclopropyl group, the crystal packing of the investigated compounds contains centrosymmetric dimers linked by paired $\mathrm{N}-\mathrm{H} \cdots \mathrm{O}$ hydrogen bonds, which further

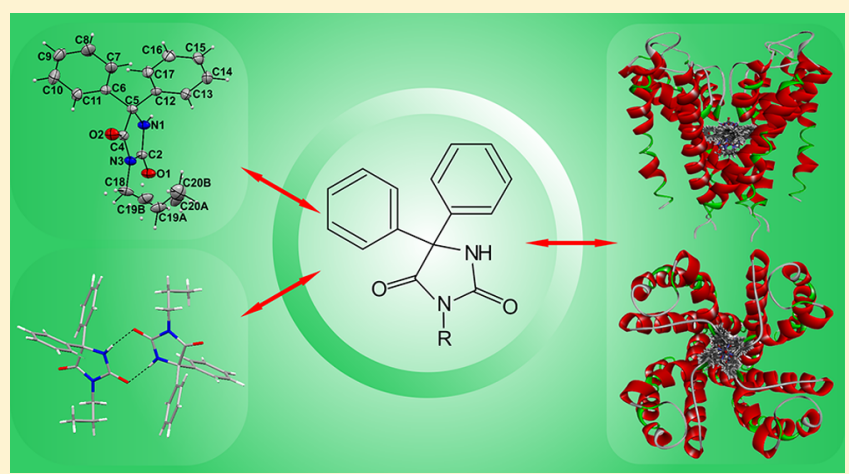
self-organize through pairs of $\mathrm{C}-\mathrm{H} \cdots \mathrm{O}$ interactions and a parallel interaction of two phenyl rings at a large offset into chains running along the $c$-axis. The principal feature of the crystal structure of compound 3 is formation of the chains by $\mathrm{N}-\mathrm{H} \cdots \mathrm{O}$ hydrogen bonds and $\mathrm{C}-\mathrm{H} \cdots \mathrm{O}$ and $\mathrm{C}-\mathrm{H} \cdots \pi$ interactions. The coordination of phenytoin enables more rotational freedom for the phenyl groups. An emphasis was placed on docking of the investigated compounds into the voltage-gated ion channel in the open and closed state. The obtained results indicate that hydrogen bonding and hydrophobic interactions are dominant in stabilizing energetically favored orientations of the investigated compounds bound to the protein.
\end{abstract}

\section{INTRODUCTION}

Phenytoin (5,5-diphenylhydantoin) is an extensively studied anticonvulsant drug that is effective in controlling seizure disorders. ${ }^{1}$ Moreover, it has class IB antiarrhythmic drug properties, and the drug is considered as an alternative for patients with refractory ventricular arrhythmia when other drugs are contraindicated. ${ }^{2,3}$ Interestingly, phenytoin possesses a variety of effects that make it potentially useful even against dermatological disorders. ${ }^{4,5}$

Molecular order of pharmaceutical solids directly influences their processing and formulation as well as important properties such as stability, dissolution rate, and, thus, bioavailability. In this context, the crystal habits and the degree of crystal defects are frequently studied in terms of their relationship to pharmaceutical properties especially of poorly aqueous soluble drugs such as phenytoin. The modification of the crystal habit is an effective approach to enhance drug solubility. Nokhodchi et al. have prepared phenytoin crystals having different types of habits by recrystallization from ethanol and acetone under various conditions. ${ }^{6}$ Crystals obtained from the ethanolic solution have a needle shape, whereas crystallization from acetone affords rhombic crystals. Irrespective of the crystallization medium, the obtained polymorph is the same in both cases. It has been further shown that the dissolution rate of different crystals is lower than that of nonrecrystallized samples, which is ascribed to the surface area of crystals with different shapes.

The crystallographic studies of the anticonvulsant drugs enable identification of structural requirements for the biological activity and provide an insight into the probable molecular environment at their binding sites. ${ }^{7,8}$ In the case of hydantoin derivatives, the crystallographic data have been applied in proposing the mechanism of action because structural elements of their binding sites are present within the molecules themselves. This comprises a combination of both hydrogen bond acceptors and donors to bind the hydantoin moiety and lipophilic groups to bind the alkyl and aryl substituents in position $\mathrm{C} 5$ of the hydantoin ring. Regarding the steric mode of

Received: November 28, 2018

Revised: February 21, 2019

Published: March 8, 2019 
behavior for hydantoin derivatives, it has been indicated that the spatial properties of these substituents relative to the rest of the molecule is an important factor in mediating the biological activity. $^{7-10}$ In this context, Camerman and Camerman have suggested that the conformational rather than chemical similarities to the conventional anticonvulsant drugs should be a criterion for the selection of novel drug candidates. ${ }^{9}$

Regarding their mechanism of action, hydantoin derivatives reduce the electrical conductance among neurons through stabilization of voltage-gated sodium channels (VGSCs) in the inactive state. ${ }^{11,12}$ These compounds have the probable binding site in the pore of the sodium channel $\alpha$-subunit consisting of four highly homologous domains (I-IV). ${ }^{13-15}$ Each domain contains six transmembrane $\alpha$-helical segments (S1-S6) which are arranged in a clockwise manner around the pore. Lipkind and Fozzard have investigated docking of phenytoin inside the inner pore of the VGSC. ${ }^{16}$ It has been shown that the N3-H group is directed to the center of the phenyl group of Phe-1764 and participates in a hydrogen bonding. One phenyl ring forms a perpendicular aromatic-aromatic interaction with Tyr-1771, whereas the second phenyl ring interacts with the side chain of Leu-1465 of DIII-S6. As expected, introduction of an alkyl substituent in position $\mathrm{N} 3$ of the hydantoin ring reduces binding. ${ }^{17}$

Although an extensive research of the biological effects of phenytoin derivatives has been performed, the dependence of the molecular order and, thus, solid-state properties on their molecular structure is still not well understood. Herein, we present a detailed study of the crystal structures of a series of phenytoin derivatives, namely, 3-alkyl-5,5-diphenylhydantoins and 3-cycloalkyl-5,5-diphenylhydantoins (Figure 1), in terms of

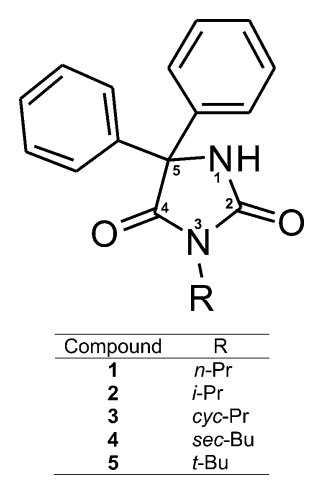

Figure 1. Chemical structures of the investigated compounds.

intermolecular interactions and packing preferences, whereby the length and branching of the alkyl group were systematically modified. These compounds have already been identified as biologically active. ${ }^{18-21}$ Their conformational analysis is based on a correlation of the conformational energies, calculated by the quantum chemical methods, with the distribution of the torsion angles between the hydantoin ring plane and planes of the phenyl rings observed in different crystal packing environments. This analysis includes phenytoin derivatives from the Cambridge Structural Database $(\mathrm{CSD})^{22}$ as well as transition metal complexes with the phenytoinate ligands that adopt various coordination geometries by small changes of steric hindrance. The crystal structures of the investigated compounds are governed by the $\mathrm{N}-\mathrm{H} \cdots \mathrm{O}$ hydrogen bonding. However, the structural diversity is a result of a large number of relatively weak intermolecular interactions. An emphasis was placed on quantitative analysis of the crystal structures in terms of the contributing intermolecular interactions and structural motifs. By examining intermolecular interactions of the investigated compounds with VGSCs, we were able to evaluate the relevance of the crystallographic data for the discussion of their anticonvulsant activity. Taking into consideration both structural and biological aspects, the presented study will afford guidelines for furthering crystal engineering to design novel hydantoin derivatives with desired pharmaceutical properties.

\section{EXPERIMENTAL SECTION}

Synthesis. All investigated compounds were previously synthesized according to the reported procedures (Scheme 1). Commercially

\section{Scheme 1. Synthesis of Investigated Compounds}

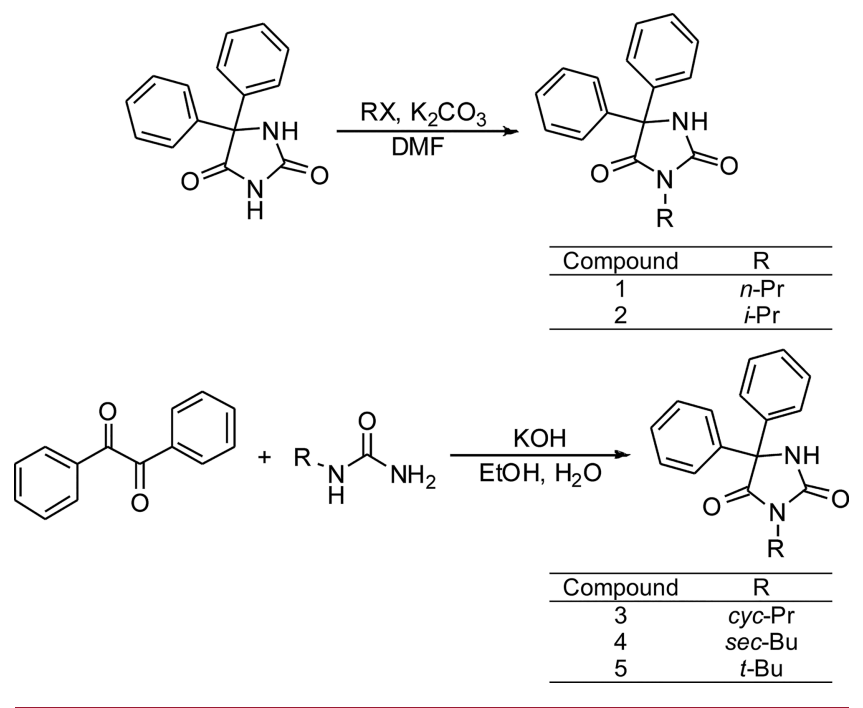

obtained phenytoin was alkylated using the corresponding alkyl halide in the presence of $\mathrm{K}_{2} \mathrm{CO}_{3}$ in $\mathrm{N}, \mathrm{N}$-dimethylformamide (DMF) to afford compounds 1 and 2 . $^{20}$ To obtain compounds $3-5$, the Bilz synthesis, consisting of the condensation of $\mathrm{N}$-substituted urea on benzil in strong basic conditions, was applied. ${ }^{23,24}$ The structures of the synthesized compounds were confirmed by their melting points, FTIR, and ${ }^{1} \mathrm{H}$ and ${ }^{13} \mathrm{C}$ NMR spectra. ${ }^{23,24}$

X-ray Structure Determination. Single crystals suitable for an Xray structure determination were obtained by slow evaporation of ethanolic solutions in refrigerator. Single-crystal X-ray diffraction data were collected at room temperature $(298 \mathrm{~K})$ on an Oxford Gemini S diffractometer equipped with CCD detector using monochromatized MoK $\alpha$ radiation $(\lambda=0.71073 \AA)$. Intensities were corrected for absorption using the multiscan method. The structures were solved by direct methods using SIR $2014^{25}$ and refined on $F^{2}$ by full-matrix leastsquares using the programs SHELXL-2018/3 ${ }^{26}$ and WinGX. ${ }^{27}$ With an exception of atoms C19 and C21 in 4 and C19A, C19B, C20A, C20B, $\mathrm{C} 21 \mathrm{~A}$, and $\mathrm{C} 21 \mathrm{~B}$ in 5, which were refined isotropically, non-hydrogen atoms were refined anisotropically. In structure 1 , two $\mathrm{C}$ atoms were disordered with congener atoms, C19A, C19B and C20A, C20B having about 40 and $60 \%$ site occupancies in both cases. Since the disordered $\mathrm{C}$ atoms as well as $\mathrm{C} 18$ in 1 belong to the same alkyl group, the positions of the hydrogen atoms bonded to $\mathrm{C} 18$ are disordered in the same way as the corresponding structural fragments within the alkyl group. In structure 5, three disordered C atoms were found, C19A, C19B; C20A, $\mathrm{C} 20 \mathrm{~B}$; and C21A, C21B with about 39 and $61 \%$ site occupancies in all cases. The positions of $\mathrm{H}$ atoms connected to $\mathrm{C}$ and $\mathrm{N}$ atoms were calculated on geometric criteria and refined by the riding model with $U_{\text {iso }}=1.2 U_{\text {eq }}(\mathrm{C}, \mathrm{N})$ and $U_{\text {iso }}=1.5 U_{\text {eq }}(\mathrm{C})$ for the methyl group. Selected crystal data and refinement results for $\mathbf{1} \mathbf{- 5}$ are listed in Table 1. CCDC 1880607-1880611 (for 1-5) contain the supplementary crystallographic data for this Article. These data can be obtained free of charge 
Table 1. Crystallographic Data and Refinement Details

\begin{tabular}{|c|c|c|c|c|c|}
\hline compound & 1 & 2 & 3 & 4 & 5 \\
\hline formula & $\mathrm{C}_{18} \mathrm{H}_{18} \mathrm{~N}_{2} \mathrm{O}_{2}$ & $\mathrm{C}_{18} \mathrm{H}_{18} \mathrm{~N}_{2} \mathrm{O}_{2}$ & $\mathrm{C}_{18} \mathrm{H}_{16} \mathrm{~N}_{2} \mathrm{O}_{2}$ & $\mathrm{C}_{19} \mathrm{H}_{20} \mathrm{~N}_{2} \mathrm{O}_{2}$ & $\mathrm{C}_{19} \mathrm{H}_{20} \mathrm{~N}_{2} \mathrm{O}_{2}$ \\
\hline molecular weight $/ \mathrm{g} \mathrm{mol}^{-1}$ & 294.34 & 294.34 & 292.33 & 308.37 & 308.37 \\
\hline crystal system & triclinic & triclinic & monoclinic & triclinic & triclinic \\
\hline space group & $P \overline{1}$ & $P \overline{1}$ & $P 2_{1} / c$ & $P \overline{1}$ & $P \overline{1}$ \\
\hline$a / \AA$ & $8.4334(6)$ & $8.5357(9)$ & $11.5996(5)$ & $8.3079(17)$ & $8.1335(16)$ \\
\hline$b / \AA ̊$ & $8.7476(7)$ & $8.6225(8)$ & $10.6459(3)$ & $9.3863(19)$ & $8.9657(18)$ \\
\hline$c / \AA$ & $12.4251(9)$ & $12.3979(9)$ & $12.2992(5)$ & $12.905(3)$ & 12.991(3) \\
\hline$\alpha / \operatorname{deg}$ & $98.501(6)$ & $104.010(7)$ & 90 & $106.09(3)$ & $102.81(3)$ \\
\hline$\beta / \operatorname{deg}$ & $95.810(6)$ & $91.826(7)$ & $101.977(4)$ & $91.97(3)$ & $93.61(3)$ \\
\hline$\gamma / \operatorname{deg}$ & $115.500(7)$ & $115.201(10)$ & 90 & $115.95(3)$ & $113.04(3)$ \\
\hline$V / \AA^{3}$ & $804.16(11)$ & $791.54(14)$ & $1485.74(10)$ & $855.2(4)$ & $838.2(4)$ \\
\hline$Z$ & 2 & 2 & 4 & 2 & 2 \\
\hline$D_{\mathrm{c}} / \mathrm{g} \mathrm{cm}^{-3}$ & 1.216 & 1.235 & 1.307 & 1.197 & 1.222 \\
\hline$\mu / \mathrm{mm}^{-1}$ & 0.08 & 0.081 & 0.086 & 0.078 & 0.08 \\
\hline$F(000)$ & 312 & 312 & 616 & 328 & 328 \\
\hline crystal size/mm & $0.92 \times 0.60 \times 0.14$ & $0.38 \times 0.23 \times 0.09$ & $0.30 \times 0.15 \times 0.12$ & $0.98 \times 0.31 \times 0.23$ & $0.85 \times 0.51 \times 0.12$ \\
\hline$\theta$ range/deg & $3.46-25.68$ & $2.67-25.68$ & $2.56-25.68$ & $3.48-25.68$ & $3.43-25.68$ \\
\hline \multirow[t]{3}{*}{ limiting indices } & $-8 \leq h \leq 10$ & $-9 \leq h \leq 10$ & $-14 \leq h \leq 14$ & $-9 \leq h \leq 10$ & $-9 \leq h \leq 9$ \\
\hline & $-10 \leq k \leq 9$ & $-10 \leq k \leq 9$ & $-12 \leq k \leq 12$ & $-9 \leq k \leq 11$ & $-10 \leq k \leq 10$ \\
\hline & $-15 \leq l \leq 12$ & $-15 \leq l \leq 15$ & $-14 \leq l \leq 14$ & $-15 \leq l \leq 11$ & $-15 \leq l \leq 15$ \\
\hline measured reflections & 5401 & 7058 & 8762 & 5970 & 12648 \\
\hline independent reflections & 3049 & 3008 & 2813 & 3122 & 3057 \\
\hline reflections with $I>2 \sigma(I)$ & 2456 & 2252 & 2327 & 2205 & 2615 \\
\hline$R_{\text {int }}$ & 0.0158 & 0.019 & 0.0224 & 0.0185 & 0.0216 \\
\hline \multirow[t]{2}{*}{ final $R$ indices $[I>2 \sigma(I)]$} & $R_{1}=0.0456$ & $R_{1}=0.0473$ & $R_{1}=0.0403$ & $R_{1}=0.0830$ & $R_{1}=0.0698$ \\
\hline & $w R_{2}=0.1023$ & $w R_{2}=0.1132$ & $w R_{2}=0.0914$ & $w R_{2}=0.2300$ & $w R_{2}=0.1822$ \\
\hline \multirow[t]{2}{*}{$R$ indices (all data) } & $R_{1}=0.0588$ & $R_{1}=0.0668$ & $R_{1}=0.0511$ & $R_{1}=0.1095$ & $R_{1}=0.0792$ \\
\hline & $w R_{2}=0.1109$ & $w R_{2}=0.1252$ & $w R_{2}=0.0974$ & $w R_{2}=0.2544$ & $w R_{2}=0.1896$ \\
\hline$S$ & 1.049 & 1.025 & 1.034 & 1.064 & 1.05 \\
\hline parameters & 218 & 199 & 199 & 197 & 201 \\
\hline$\Delta \rho_{\max } \Delta \rho_{\min } / \mathrm{e} \AA^{-3}$ & $0.175,-0.157$ & $0.163,-0.168$ & $0.266,-0.281$ & $0.512,-0.536$ & $0.564,-0.423$ \\
\hline
\end{tabular}

from The Cambridge Crystallographic Data Centre via www.ccdc.cam. ac.uk.

Theoretical Study. To determine the crystal packings and how the orientation of the phenyl groups affects the stability of phenytoin derivatives, the quantum-chemical calculations at wb97xd/6-31+G** level were performed in Gaussian09 program. ${ }^{28}$ The optimized structure of compound $\mathbf{1}$ and the structure of hydantoin-metal complex, extracted from the crystal structure with refcode IPOYUI, ${ }^{29}$ were used as the model systems to evaluate the impact of the phenyl group orientations on the stability of phenytoin derivatives. To estimate the strength of interactions between individual fragments of the studied systems, the quantum-chemical calculations on the cyclopropane/ benzene, cyclopropane/hydantoin, propane/benzene, and propane/ hydantoin model systems were carried out at wb97xd/6-31+G** level.

The binding of the investigated compounds to the neuronal $\mathrm{Na}^{+}$ channel in the open state (open channel model by Lipkind and Fozzard $)^{16}$ and the closed state $\left(\mathrm{K}^{+}\right.$channel; the structure was obtained from the crystal structure with pdb code $1 B L 8)^{30}$ was explored by docking simulations with the aim to investigate their anticonvulsant ability on the basis of the binding affinity to the ion channel. Their structures were optimized at wb97xd/6-31+G** level. AutoDock 4.2 software program ${ }^{31}$ was used for docking calculations and preparation of protein structure, which included the addition of the hydrogen atoms and removal of ligands from the crystal structure. The structure of proteins was considered as a rigid species, while phenytoin derivatives were allowed to rotate freely. Grid box with whole protein was used to accommodate phenytoin derivatives during the docking study, the Geister partial charges were allocated during docking simulations, while the Lamarckian genetic algorithm was used as the search method for virtual screening, with 50 runs for each docking screen.

\section{RESULTS AND DISCUSSION}

Molecular Structure. Representative ORTEP diagrams of the investigated compounds $\mathbf{1 - 5}$ are shown in Figure 2, while selected bond lengths and angles are listed in Table S1. The geometric parameters are very close to those of hydantoin derivatives described previously. ${ }^{32-36}$ The hydantoin ring is nearly planar. The $\pi$-conjugation within the imide fragments results in the length of the $\mathrm{N} 1-\mathrm{C} 2$ and $\mathrm{N} 3-\mathrm{C} 4$ bonds falling in the shortest ones (average 1.34 and $1.37 \AA$, respectively). However, the $\mathrm{C} 4-\mathrm{C} 5$ and $\mathrm{N} 1-\mathrm{C} 5$ bonds have a $\sigma$ character, and they are the longest in the hydantoin ring (average 1.54 and $1.46 \AA$, respectively). With the exception of compound 3 , the $\mathrm{C} 4=\mathrm{O} 2$ bond is slightly shorter than the $\mathrm{C} 2=\mathrm{O} 1$ bond. The $\mathrm{N} 3-\mathrm{C} 18$ bond between the hydantoin ring and (cyclo)alkyl substituent shows a $\sigma$ character with the average length of 1.47 $\AA$. In addition, this bond in compound 3 is slightly shorter than the average value, while it is longer than the average in compound $\mathbf{5}$.

Intramolecular Interactions: Mutual Orientations of the Phenyl and Hydantoin Rings. The ability of the carbonyl and $\mathrm{N}-\mathrm{H}$ groups of phenytoin to form intermolecular hydrogen bonds is presumably responsible for the anticonvulsant action of this drug. However, an in vitro study of the sodium channel binding activity of several 5-phenylhydantoins has suggested that the orientation of the phenyl groups is important for an efficient binding. ${ }^{10}$ The results have revealed that the derivative with the methyl group in the ortho position of one phenyl ring possesses the higher rotational energy barrier and exhibits a 


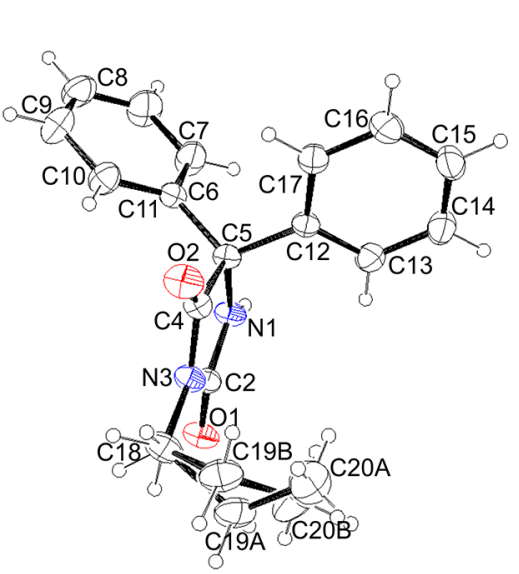

1

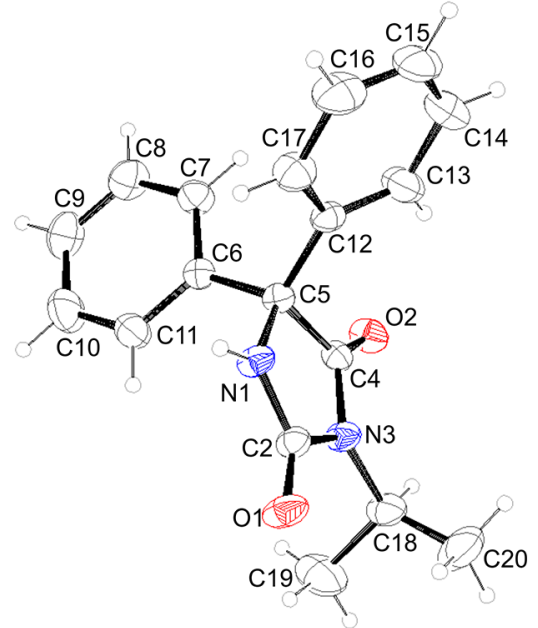

2

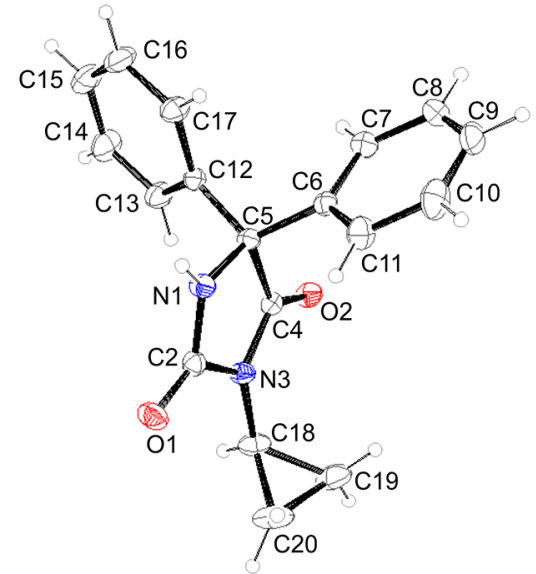

3
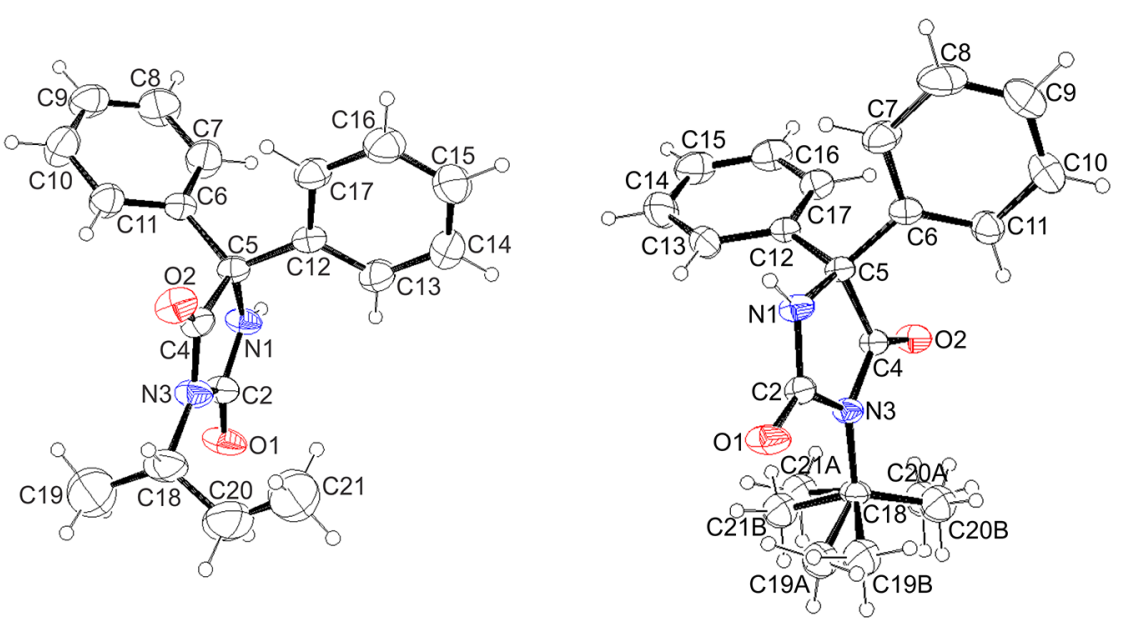

4

Figure 2. ORTEP image of the investigated phenytoin derivatives.

corresponding decrease in the sodium channel binding activity when compared to phenytoin and the derivatives with the metaand para-methyl substituents. In addition, this study puts a particular emphasis on the importance of the mutual orientation of the phenyl and hydantoin rings for the anticonvulsant activity of hydantoin derivatives.

To determine the mutual orientation of the phenyl rings, the $\mathrm{P}_{1} / \mathrm{P}_{2}$ parameter was introduced as a measure of the angle between the planes of the phenyl rings. The orientation of the phenyl groups relative to the hydantoin ring is defined with two torsion angles, $\tau_{1}$ and $\tau_{2}$ (Figure 3 ). These torsion angles are defined with respect to the carbonyl $\mathrm{C} 4=\mathrm{O} 2$ group and labeled as $\mathrm{C} 11-\mathrm{C} 6-\mathrm{C} 5-\mathrm{C} 4\left(\tau_{1}\right)$ and $\mathrm{C} 4-\mathrm{C} 5-\mathrm{C} 12-\mathrm{C} 13\left(\tau_{2}\right)$, where $\mathrm{C} 11$ and $\mathrm{C} 13$ belong to the phenyl $\mathrm{C}-\mathrm{H}$ groups closest to the carbonyl group (Figure 3 ). The parameters $\tau_{1}$ and $\tau_{2}$ can have values in the range from 0 to $180^{\circ}$, while positive values of the torsion angles refer to orientations in which the phenyl C6-C11 and $\mathrm{C} 12-\mathrm{C} 13$ bonds rotate from the carbonyl to $\mathrm{N}-\mathrm{H}$ group of the hydantoin ring. Therefore, the torsion values close to 0 and $180^{\circ}$ correspond to the orientations with $\mathrm{C}-\mathrm{H} \cdots \pi$ interactions between the phenyl and carbonyl $\mathrm{C} 4=\mathrm{O} 2$ group, while the torsions in which the values are close to $100^{\circ}$ (N1-C5-C4 angle is close to $100^{\circ}$ ) correspond to the orientations with $\mathrm{C}-$ $\mathrm{H} \cdots \mathrm{N}$ interactions. Analysis of the geometric parameters for the

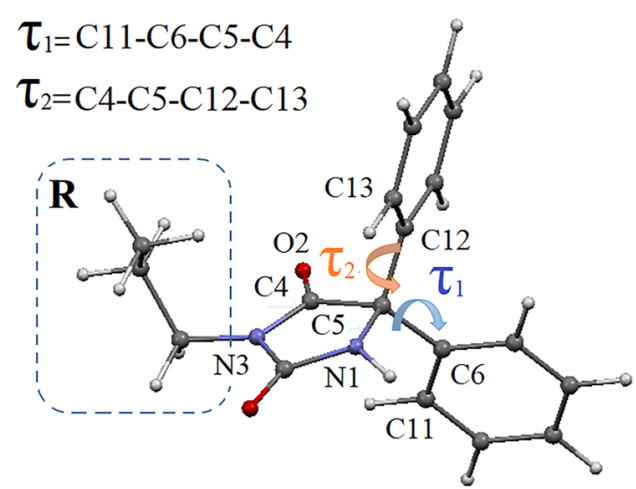

Figure 3. Optimized compound $\mathbf{1}$ used as the model system for description of the ring orientation in the investigated compounds and DFT calculations with the displayed geometric parameters and labels of the corresponding atoms.

investigated compounds, taken from X-ray structure data (Table 2 ), showed that, in all structures, one phenyl group forms a C$\mathrm{H} \cdots \mathrm{N}$ interaction with atom $\mathrm{N} 1$ of the hydantoin ring, while the second one forms a $\mathrm{C}-\mathrm{H} \cdots \pi$ interaction with the carbonyl $\mathrm{C} 4=$ $\mathrm{O} 2$ group. The phenyl groups have orientations close to orthogonal $\left(\mathrm{P}_{1} / \mathrm{P}_{2} \approx 90^{\circ}\right)$, thus forming a $\mathrm{C}-\mathrm{H} \cdots \pi$ interaction. 
Table 2. Geometric Parameters That Describe the Orientation of the Rings in the Crystal Structure of the Investigated Compounds

\begin{tabular}{clrrc} 
& & \multicolumn{3}{c}{ geometric parameter, deg } \\
\cline { 3 - 5 } compound & $\mathrm{R}$ & $\tau_{1}$ & $\tau_{2}$ & $\mathrm{P}_{1} / \mathrm{P}_{2}$ \\
\cline { 3 - 5 } $\mathbf{1}$ & $n-\mathrm{Pr}$ & 100.2 & 173.8 & 87.9 \\
$\mathbf{2}$ & $i-\mathrm{Pr}$ & 79.8 & 157.8 & 88.7 \\
$\mathbf{3}$ & $c y c-\mathrm{Pr}$ & 15.1 & 91.4 & 73.6 \\
$\mathbf{4}$ & sec-Bu & 93.8 & 4.5 & 79.8 \\
$\mathbf{5}$ & $t$-Bu & 97.0 & 5.0 & 81.4 \\
\hline
\end{tabular}

To determine how the orientation of the phenyl groups affects the stability of the investigated compounds, the quantumchemical calculations were performed. The optimized structure of compound 1 containing the propyl group in position N3, taken from the $\mathrm{X}$-ray analysis, was used as the model system. The values of the torsion angles $\tau_{1}$ and $\tau_{2}$ were systematically varied from 0 to $180^{\circ}$ in steps of $30^{\circ}$. The positive values of $\tau_{1}$ and $\tau_{2}$ parameters correspond to rotations around the $\mathrm{C} 5-\mathrm{C} 6$ and $\mathrm{C} 5-\mathrm{C} 12$ bonds, in which the projection of the $\mathrm{C} 6-\mathrm{C} 11$ and $\mathrm{C} 12-\mathrm{C} 13$ bonds onto the mean plane of the hydantoin ring moves toward its center.

To understand the mutual orientation of the rings, selected values of the torsion angles $\tau_{1}$ and $\tau_{2}$ are presented: $0^{\circ}$, the projection of the ortho- $\mathrm{C}-\mathrm{H}$ group of the phenyl ring matches the direction of the $\mathrm{C} 5-\mathrm{C} 4$ bond of the hydantoin ring (groups form a $\mathrm{C}-\mathrm{H} \cdots \pi$ interaction); $50^{\circ}$, the projection of the ortho$\mathrm{C}-\mathrm{H}$ group of the phenyl ring passes through the centroid of the hydantoin ring (groups form a $\mathrm{C}-\mathrm{H} \cdots \pi$ interaction); $100^{\circ}$, the projection of the ortho- $\mathrm{C}-\mathrm{H}$ group of the phenyl ring matches the direction of the $\mathrm{N} 1-\mathrm{C} 5$ bond of the hydantoin ring (groups form a $\mathrm{C}-\mathrm{H} \cdots \mathrm{N}$ interaction); greater than $100^{\circ}$, the projection of the ortho- $\mathrm{C}-\mathrm{H}$ groups of the phenyl ring is outside the hydantoin ring.

Based on the results of calculations, some general conclusions can be derived (Table 3). The unfavorable geometries (with energies less than $120 \mathrm{kcal} / \mathrm{mol}$ ) occur when the interacting phenyl $\mathrm{C}-\mathrm{H}$ groups have similar values of $\tau_{1}$ and $\tau_{2}$ angles, and both groups are located above the carbonyl $\mathrm{C} 4=\mathrm{O} 2$ group $\left(\tau_{1}\right.$ and $\tau_{2}$ have values close to 0 or $180^{\circ}$ ), above the $\mathrm{N} 1-\mathrm{H}$ group

Table 3. Relative Energies (in $\mathrm{kcal} / \mathrm{mol}$ ) of the Investigated Compounds (Calculated with Respect to the Most Unstable Orientation of the Phenyl Rings) as a Function of the $\tau_{1}$ and $\tau_{2}$ Torsion Angle Values ${ }^{a}$

\begin{tabular}{cccccccc}
\hline$\tau_{1} \downarrow \tau_{2} \rightarrow$ & $0^{\circ}$ & $30^{\circ}$ & $60^{\circ}$ & $90^{\circ}$ & $120^{\circ}$ & $150^{\circ}$ & $180^{\circ}$ \\
\hline $0^{\circ}$ & -117.1 & -115.6 & -129.0 & -132.2 & -129.8 & -128.4 & -117.1 \\
$30^{\circ}$ & -115.4 & 0.0 & -95.3 & -129.0 & -130.4 & -129.6 & -115.4 \\
$60^{\circ}$ & -128.8 & -95.2 & $* * *$ & -105.4 & -128.6 & -131.0 & -128.8 \\
$90^{\circ}$ & $-\mathbf{1 3 3 . 3}$ & -130.2 & -106.7 & -90.0 & -126.4 & -131.9 & $-\mathbf{1 3 3 . 3}$ \\
$120^{\circ}$ & -132.4 & -133.2 & -131.6 & -128.2 & -128.7 & -131.1 & -132.4 \\
$150^{\circ}$ & -129.5 & -130.8 & -132.4 & -132.0 & -129.5 & -129.5 & -129.5 \\
$180^{\circ}$ & -117.1 & -115.6 & -129.0 & -132.2 & -129.8 & -128.4 & -117.1 \\
\hline
\end{tabular}

${ }^{a}$ Orientations with energies up to $10 \mathrm{kcal} / \mathrm{mol}$ less than the most stable orientation are marked with the dark gray background; the orientations with energies for $10-20 \mathrm{kcal} / \mathrm{mol}$ less than the most stable orientation are marked with the light gray background; the least stable orientations are marked with the white background. ***For this orientation, a small interatomic $\mathrm{H} \cdots \mathrm{H}$ distance was encountered (Figure 4). $\left(\tau_{1}=\tau_{2}=90^{\circ}\right)$ or close to the centroid of the hydantoin ring $\left(\tau_{1}\right.$ $=\tau_{2}=60^{\circ}$ ).

In the most stable geometry $\left(\tau_{1}=90^{\circ}\right.$ and $\left.\tau_{2}=0^{\circ}\right)$, the ortho$\mathrm{C}-\mathrm{H}$ group of the first phenyl group interacts with the carbonyl $\mathrm{C} 4=\mathrm{O} 2$ group of the hydantoin ring (form a $\mathrm{C}-\mathrm{H} \cdots \pi$ interaction), with the $\mathrm{C} 4 \cdots \mathrm{H}$ distance of $2.38 \AA$. The ortho$\mathrm{C}-\mathrm{H}$ group from the second phenyl group interacts with atom $\mathrm{N} 1$ of the hydantoin ring (form a $\mathrm{C}-\mathrm{H} \cdots \mathrm{N}$ interaction) with the $\mathrm{H} \cdots \mathrm{N} 1$ distance of $2.34 \AA$. The phenyl rings have a geometry close to $\mathrm{T}$-shape $\left(\mathrm{P}_{1} / \mathrm{P}_{2}\right.$ angle of $\left.72.7^{\circ}\right)$, building a $\mathrm{C}-\mathrm{H} \cdots \pi$ interaction with distance between centroids of $3.26 \AA$ (Figure $4)$. However, in the least stable geometry $\left(\tau_{1}=\tau_{2}=60^{\circ}\right)$, the
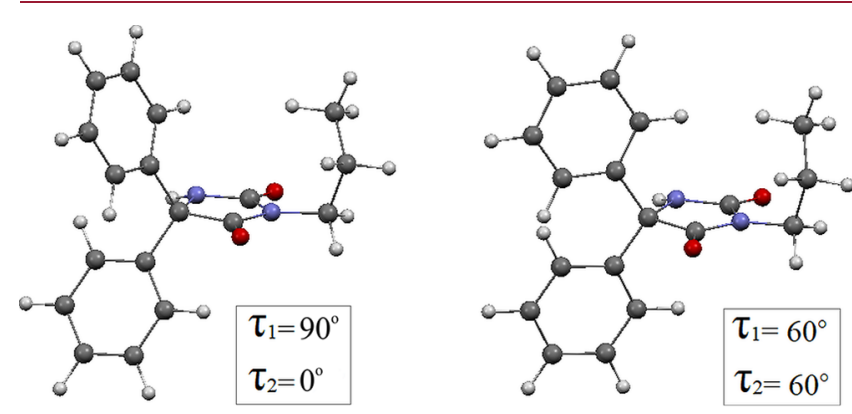

Figure 4. Illustration of the most stable geometry (left, $\tau_{1}=90^{\circ}$ and $\tau_{2}=$ $0^{\circ}$ ) and the least stable geometry (right, $\tau_{1}=\tau_{2}=60^{\circ}$ ) of optimized compound 1.

ortho- $\mathrm{C}-\mathrm{H}$ group of both phenyl groups interacts with the centroid of the hydantoin ring $(\Omega)$ with the $\mathrm{H} \cdots \Omega$ distances of $2.62 \AA$. The phenyl rings are planar $\left(\mathrm{P}_{1} / \mathrm{P}_{2}\right.$ angle of $\left.0^{\circ}\right)$ with an unfavorable short $\mathrm{H} \cdots \mathrm{H}$ contact (Figure 4 ).

Based on the presented results, one can conclude that orientations of the rings in the crystal structures of the investigated compounds correspond to the most stable calculated geometry (Figure 4, left) and indicate that the size and orientations of the selected substituents do not have significant influence on the orientation of the rings.

The range of the torsion angles defining the relative orientation of the phenyl groups of phenytoin is wider in the solid state than in solution. ${ }^{37}$ However, the range of the torsion angles that characterize the relative orientation of the hydantoin and phenyl rings is more narrow in the solid state. ${ }^{37}$ To examine the influence of substitution in position $\mathrm{N} 3$ of the hydantoin ring, the crystal structures of uncoordinated phenytoin derivatives were extracted from the CSD, as well as the geometric data describing the mutual orientation of the phenyl and hydantoin rings $\left(\mathrm{P}_{1} / \mathrm{P}_{2}\right.$ parameter; torsion angles $\tau_{1}$ and $\left.\tau_{2}\right)$. Results of statistical analysis (Figure 5) showed that the phenyl groups are generally located above the carbonyl $\mathrm{C} 4=\mathrm{O} 2$ group $\left(\tau_{1}\right.$ and $\tau_{2}$ have values close to 0 or $180^{\circ}$ ) or close to the $\mathrm{N} 1-\mathrm{H}$ group $\left(\tau_{1}\right.$ and $\tau_{2}$ have values close to $\left.100^{\circ}\right)$. As in the case of the investigated compounds, the phenyl groups of the extracted structures have nearly orthogonal orientations $\left(\mathrm{P}_{1} / \mathrm{P}_{2} \approx 90^{\circ}\right)$.

In the structures with the projections of the phenyl rings outside the hydantoin ring, the neighboring molecule is located above the hydantoin ring and simultaneously interacts with the hydantoin and phenyl groups. These orientations $\left(150^{\circ} \geq \tau_{1} \geq\right.$ $120^{\circ}$ and $150^{\circ} \geq \tau_{2} \geq 120^{\circ}$ ) are energetically favorable (orientations with dark gray background in Table 3 ) in comparison to the orientations in which both phenyl groups are located above the hydantoin ring. In the crystal structure of 3 -amino derivative of phenytoin (refcode NIXTAR, ${ }^{38}$ Figure 6), 

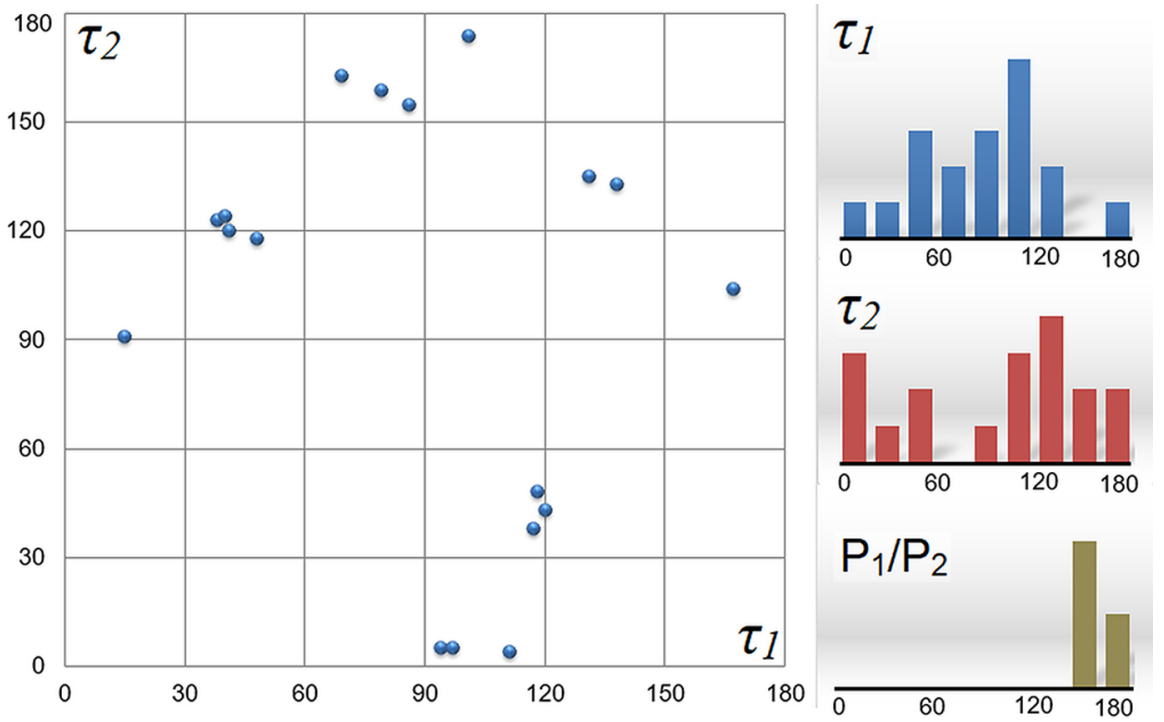

Figure 5. Distributions of the geometric parameters describing the mutual orientation of the phenyl and hydantoin rings $\left(\mathrm{P}_{1} / \mathrm{P}_{2}\right.$ parameter; $\tau_{1}$ and $\tau_{2}$ torsion angles) in the crystal structures of uncoordinated phenytoin derivatives. The graphs show the distributions of the parameters for compounds 1-5 and 13 structures extracted from the CSD.

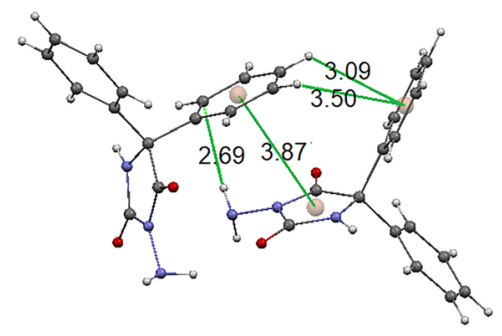

Figure 6. Illustration of the crystal packing of 3-amino-5,5diphenylhydantoin with refcode NIXTAR. ${ }^{38}$

the phenyl group of the first molecule is positioned above the hydantoin ring of the second one. This phenyl group simultaneously forms a stacking interaction with the hydantoin ring (distance between the centroids of the rings is $3.87 \AA$ ), a N$\mathrm{H} \cdots \pi$ with the amino group (normal distances of the amino $\mathrm{H}$ atom to the mean plane of the phenyl ring is $2.69 \AA$ ), and a bifurcated $\mathrm{C}-\mathrm{H} \cdots \pi$ interaction with the phenyl group from the second molecule (distances of $\mathrm{H}$ atoms from the centroids of the second phenyl ring are 3.09 and $3.50 \AA$ ). The geometries in which one phenyl group is located above the $\mathrm{N} 1-\mathrm{H}$ group, while the second one is close to the carbonyl $\mathrm{C} 4=\mathrm{O} 2$ group, are less frequent in the crystal structures, despite the similarities in the energies with geometries where the phenyl rings are outside the hydantoin ring (Table 3 and Figure 5). This geometry occurs in the structures bearing a bulky substituent in position $\mathrm{N} 3$ of the hydantoin ring (structure with refcode JALGEL, ${ }^{39}$ Figure S1), which sterically hinders the access of species from the environment to the hydantoin ring. These examples demonstrate the importance of voluminosity of the substituent on the mutual orientation of the hydantoin and phenyl rings and, consequently, on the interactions of phenytoin derivatives with species from the environment.

Intermolecular Interactions: Crystal Packing. The basic structural motif in the crystal packing of compounds 1, 2, 4, and 5 represents a centrosymmetric dimer (dimeric motif D11, Figure 7), where two molecules are connected by two $\mathrm{N}-\mathrm{H} \cdots \mathrm{O}$ hydrogen bonds (distance $d_{1}$, Table 4 ) with interaction energy from -13.48 (compound 5) to $-14.61 \mathrm{kcal} / \mathrm{mol}$ (compound
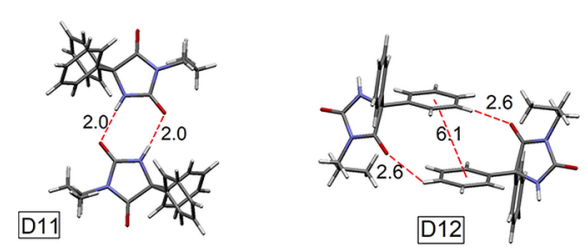
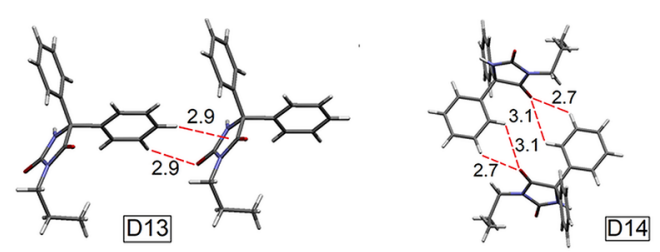

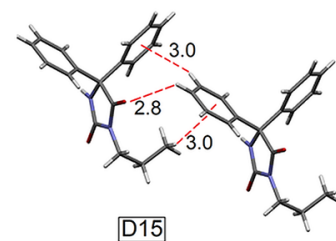

D15

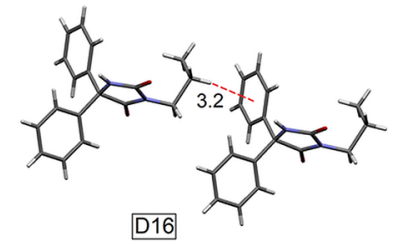

$\overline{D 16}$

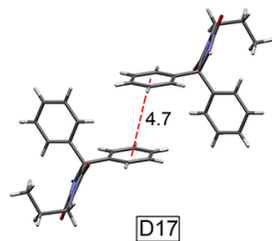

D17

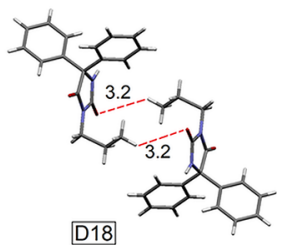

D18

Figure 7. Typical structural motifs identified in the crystal structures of compound $\mathbf{1}$ used as an illustration of the crystal packing in compounds 1, 2, 4, and 5. Only the crystal packing of compounds $\mathbf{1}$ and $\mathbf{5}$ contains the dimeric motif D14. 
Table 4. Geometric Parameters (in $\AA$ ) and Interaction Energies (in kcal/mol) for the Dimeric Motifs in the Crystal Packing of the Investigated Phenytoin Derivatives 1, 2, 4, and 5

\begin{tabular}{|c|c|c|c|c|c|}
\hline \multirow{2}{*}{$\begin{array}{c}\text { dimeric } \\
\text { motif }\end{array}$} & \multirow[b]{2}{*}{ parameter } & \multicolumn{4}{|c|}{ compound, $\mathrm{x}$} \\
\hline & & 1 & $2^{a}$ & 4 & 5 \\
\hline \multirow[t]{2}{*}{ Dx1 } & $d_{1}$ & 2.00 & 2.00 & 2.02 & 2.01 \\
\hline & $\Delta E_{1}$ & 14.61 & -14.50 & -14.00 & -13.48 \\
\hline \multirow[t]{3}{*}{$\mathrm{Dx} 2$} & $d_{2}$ & 2.62 & $2.79(3.11)$ & 2.64 & 3.02 \\
\hline & $d_{3}$ & 6.13 & $6.66(6.00)$ & 6.10 & 6.45 \\
\hline & $\Delta E_{2}$ & -5.81 & $-4.89(-4.91)$ & -6.59 & -5.50 \\
\hline \multirow[t]{3}{*}{$\mathrm{Dx} 3$} & $d_{4}$ & 2.93 & 3.15 & 3.73 & 3.27 \\
\hline & $d_{5}$ & 2.86 & 3.12 & 3.81 & 3.36 \\
\hline & $\Delta E_{3}$ & -4.89 & -5.72 & -3.62 & -4.40 \\
\hline \multirow[t]{3}{*}{$\mathrm{Dx} 4$} & $d_{6}$ & 2.70 & & & 2.74 \\
\hline & $d_{7}$ & 3.10 & & & \\
\hline & $\Delta E_{4}$ & -7.05 & & & -5.92 \\
\hline \multirow[t]{4}{*}{ Dx5 } & $d_{8}$ & 2.84 & 2.68 & 2.83 & 2.80 \\
\hline & $d_{9}$ & 2.97 & & 3.42 & 3.42 \\
\hline & $d_{10}$ & 3.00 & & 3.02 & 3.27 \\
\hline & $\Delta E_{5}$ & -7.05 & -4.33 & -6.16 & -6.35 \\
\hline \multirow[t]{3}{*}{ Dx6 } & $d_{11}$ & 3.19 & 3.29 & 3.55 & 2.80 \\
\hline & $d_{12}$ & & 3.29 & 3.58 & \\
\hline & $\Delta E_{6}$ & -4.39 & -4.83 & -3.93 & -5.00 \\
\hline \multirow[t]{2}{*}{ Dx7 } & $d_{13}$ & 4.70 & $4.56(5.89)$ & 4.71 & 4.81 \\
\hline & $\Delta E_{7}$ & -3.99 & $-4.27(-2.45)$ & -4.89 & -4.02 \\
\hline \multirow[t]{3}{*}{ Dx8 } & $d_{14}$ & 3.25 & $3.51(3.35)$ & 2.99 & 3.23 \\
\hline & $d_{15}$ & 3.25 & $3.51(3.35)$ & 2.99 & 3.23 \\
\hline & $\Delta E_{8}$ & -4.89 & $-4.24(-2.38)$ & -5.86 & -5.15 \\
\hline
\end{tabular}

${ }^{a}$ Values in the parentheses refer to the second orientation within the same dimeric motif.

1). This motif possesses the highest interaction energy in all mentioned systems. These structural motifs are further linked into chains running along the $c$-axis (dimeric motif D12, Figure 7) and mutually form two $\mathrm{C}-\mathrm{H} \cdots \mathrm{O}$ interactions between the $\mathrm{C}-\mathrm{H}$ group of the phenyl rings and the carbonyl $\mathrm{O}$ atom (distance $d_{2}$, Table 4) as well as a parallel interaction of two phenyl rings at a large offset (distance between centroids $d_{3}$, Table 4). Within the chains, the planes of the hydrogen-bonded motifs are mutually parallel. Viewed from the direction of the $a$ axis (Figure 8a), the phenyl groups are arranged alternately on different sides of the secondary chain containing only the hydantoin rings (framed with a red box). In the direction of the $b$-axis (Figure $8 \mathrm{~b}$ ), the alkyl and phenyl groups are arranged alternately on the same side of the secondary chain.

The chains are further linked in layers parallel to the $b c$-plane (Figure $8 c, d$ ), whereby every basic motif interacts with three motifs from the neighboring chains. The $\mathrm{C}-\mathrm{H} \cdots \pi$ and $\mathrm{C}-\mathrm{H} \cdots \mathrm{O}$ interactions between the phenyl and hydantoin rings (distances $d_{4}$ and $d_{5}$, Table 4) promote dimerization of these motifs from the neighboring chains along the $b$-axis (dimeric motif D13, Figure 7). In the crystal packing of $\mathbf{1}$ and $\mathbf{5}$, a centrosymmetric dimeric motif is generated by the bifurcated $\mathrm{C}-\mathrm{H} \cdots \mathrm{O}$ interactions (distances $d_{6}$ and $d_{7}$, Table 4 ) between the phenyl $\mathrm{C}-\mathrm{H}$ groups and hydantoin $\mathrm{C} 2=\mathrm{O} 4$ group (dimeric motif D14, Figure 7).

The layers pile up along the $a$-axis to form a three-dimensional framework structure in which every basic motif interacts with four others from the neighboring layers. Four independent motifs can be further recognized. One of them (dimeric motif $\mathrm{D} 15$, Figure 7) is formed through a $\mathrm{C}-\mathrm{H} \cdots \mathrm{O}$ interaction between the phenyl ring and the carbonyl $\mathrm{O}$ atom (distance $d_{8}$, Table 4), $\mathrm{C}-\mathrm{H} \cdots \pi$ interactions between the phenyl rings (distance $d_{9}$, Table 4 ), as well as between the alkyl group and $\pi$ system of the phenyl group (distance $d_{10}$, Table 4). The motifs from the adjacent layers interact along a direction extending between the $a$ - and $b$-axes (dimeric motif D16, Figure 7). The propyl group forms a $\mathrm{C}-\mathrm{H} \cdots \pi$ interaction with the $\pi$-system of the phenyl group (distances $d_{11}$, Table 4 ). However, the analyzed structures $\mathbf{2}$ and $\mathbf{4}$ slightly differ in this dimeric motif. Namely, in these structures the alkyl group forms the bifurcated $\mathrm{C}-\mathrm{H} \cdots \pi$ interactions (distances $d_{11}$ and $d_{12}$, Table 4). In the third motif (dimeric motif D17, Figure 7 ), two phenyl groups form stacking interactions $\left(d_{13}\right.$ distance between centroids, Table 4$)$, with the interaction energy of $-3.57 \mathrm{kcal} / \mathrm{mol}$. The propyl group interacts with the hydantoin $\mathrm{C} 2=\mathrm{O} 4$ group (dimeric motif D18, Figure 7), through two $\mathrm{C}-\mathrm{H} \cdots \mathrm{O}$ interactions of the same geometries (distances $d_{14}$ and $d_{15}$, Table 4).

Although these motifs occur in almost every analyzed structure, the differences in the length and branching of the alkyl group result in a slight difference in the geometries of the particular motifs, but not in the overall crystal packing. The geometries of these motifs in the crystal structures of $\mathbf{2 , 4}$, and 5 are shown in Supporting Information Figures S2-S4.

In contrast to other structures, compound 3, which contains the cyclopropyl group, does not form the centrosymmetric

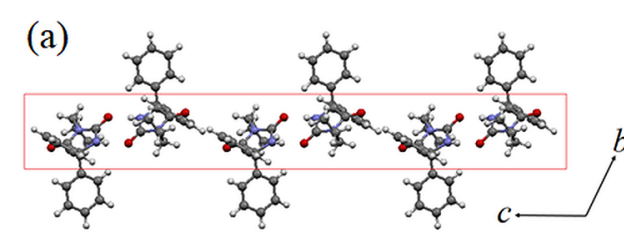

(b)

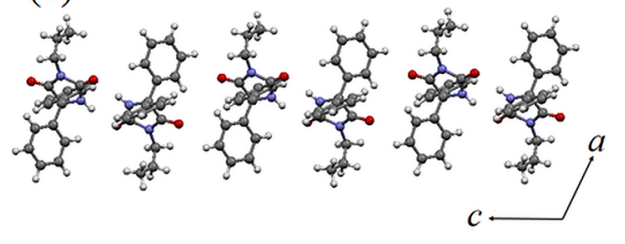

(c)

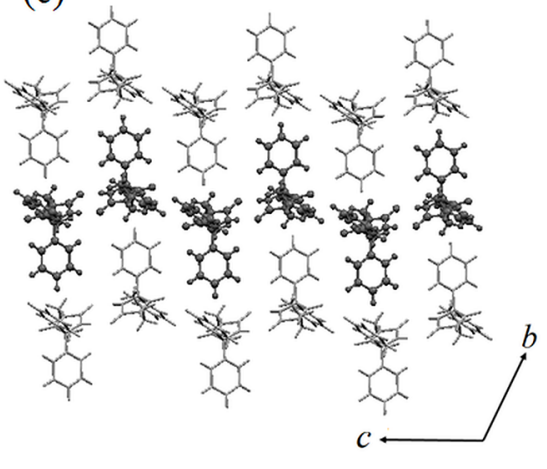

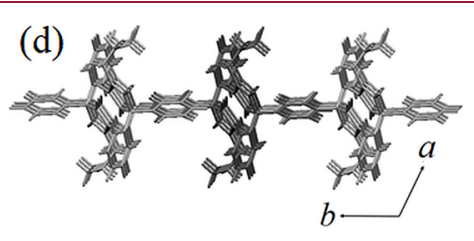

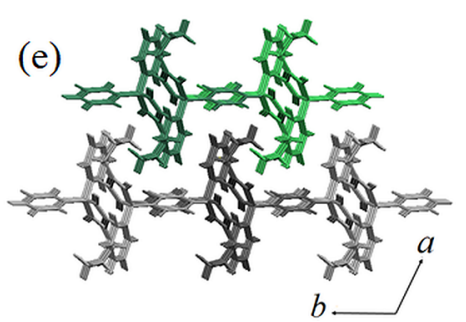

Figure 8. Crystal packing of compounds 1, 2, 4, and 5. 
hydrogen-bonded dimeric motif. The basic structural motif represents a dimer (Figure 9) consisting of molecules linked by

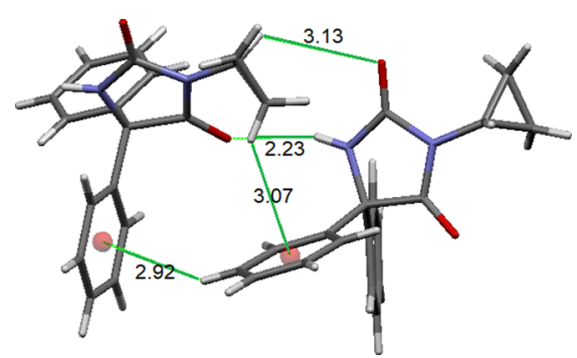

Figure 9. Basic motif in the crystal structure of compound 3.

one $\mathrm{N}-\mathrm{H} \cdots \mathrm{O}$ hydrogen bond, one $\mathrm{C}-\mathrm{H} \cdots \mathrm{O}$ interaction, and two $\mathrm{C}-\mathrm{H} \cdots \pi$ interactions. The hydrogen bonding occurs between the $\mathrm{N}-\mathrm{H}$ group and the carbonyl $\mathrm{O}$ atom of two neighboring hydantoin rings (distance $2.23 \AA$ ). The $\mathrm{C}-\mathrm{H} \cdots \pi$ interactions are formed between two phenyl groups (distance $2.92 \AA$ ) as well as the cyclopropyl and phenyl groups (distance $3.07 \AA$ ). The cyclopropyl group additionally forms a $\mathrm{C}-\mathrm{H} \cdots \mathrm{O}$ interaction with the carbonyl O atom (distance $3.13 \AA$ ). The interaction energy for this dimeric motif is $-13.89 \mathrm{kcal} / \mathrm{mol}$, which is slightly smaller than the interaction energies of the previously described basic motifs (with the exception of compound 5).

Along the $c$-axis the basic motifs form a chain (Figure 10a) in which each molecule interacts in the same manner with the neighboring molecules, as in the basic motif (one $\mathrm{N}-\mathrm{H} \cdots \mathrm{O}$ hydrogen bond, two $\mathrm{C}-\mathrm{H} \cdots \pi$ interactions, and one $\mathrm{C}-\mathrm{H} \cdots \mathrm{O}$ interaction). Viewed along the $b$-axis, the phenyl groups are located to the same side of the secondary chain containing the hydrogen-bonded hydantoin rings, while the cyclopropyl groups are on the other side (Figure 10a). Parallel to the $b c$-plane, the chains build layers (Figure 10b) connected by aromatic interactions of the phenyl rings at a large displacement (the shortest distance between centroids is $6.64 \AA$ ). Within the layer, the chains are oriented in such a manner that the phenyl groups are located to one side of the layer, while the cyclopropyl groups are located to the opposite side (Figure 10c). Along the $a$-axis, the layers form a three-dimensional framework structure in which the phenyl regions of the neighboring layers are in contact, while the cyclopropyl regions interact with each other (Figure 10d).

In the phenyl contact region, three different dimeric motifs are observed: two motifs with stacking interactions of the phenyl rings, while in the third motif molecules simultaneously form a $\mathrm{C}-\mathrm{H} \cdots \mathrm{O}$ interaction (between the phenyl and carbonyl groups) and the $\pi \cdots \pi$ aromatic interaction at a large distance of centroids (motifs Df1-Df3, Figure S5). The interaction energies for these orientations range from -4.20 to $-5.38 \mathrm{kcal} / \mathrm{mol}$. However, there are also three dimeric motifs (Dc1-Dc3, Figure S5): two of them with the simultaneous $\mathrm{C}-\mathrm{H} \cdots \mathrm{O}$ interactions of the phenyl and carbonyl groups (interaction energies are -7.04 and $-8.51 \mathrm{kcal} / \mathrm{mol}$ ), while in the third motif the cyclopropyl group is an $\mathrm{H}$-donor for the $\mathrm{C}-\mathrm{H} \cdots \mathrm{O}$ interaction with the carbonyl group (interaction energy is $-3.16 \mathrm{kcal} / \mathrm{mol}$ ).

By comparing the crystal packings of compounds 1 and 3, it can be noted that the propyl group has a tendency toward the $\mathrm{C}-\mathrm{H} \cdots \pi$ interactions with the phenyl group, while the cyclopropyl group forms mostly the $\mathrm{C}-\mathrm{H} \cdots \mathrm{O}$ interactions with the carbonyl group of the hydantoin ring. In addition, the cyclopropyl group forms the $\mathrm{C}-\mathrm{H} \cdots \pi$ interactions with the phenyl groups, as well as the aromatic interactions at a large displacement. To explain the trends observed in the crystal packings, the quantum-chemical calculations were carried out on the cyclopropane/benzene, cyclopropane/hydantoin, propane/benzene, and propane/hydantoin model systems at wb97xd/6-31+G** level. The starting model systems contain the propane (or cyclopropane) group positioned above the benzene or hydantoin ring or outside these rings, with the parallel and T-shaped geometry of the interacting species. The optimized orientations and their interaction energies are shown in Figures 11 and 12.

Cyclopropane has a greater tendency to position above the benzene ring (to build a $\mathrm{C}-\mathrm{H} \cdots \pi$ interaction) and outside the hydantoin ring (to build a $\mathrm{C}-\mathrm{H} \cdots \mathrm{O}$ interaction) (Figures 11). In contrast, propane has a greater tendency to localize above the benzene and hydantoin ring (Figures 12). However, in the crystal structure of compound $\mathbf{1}$, the phenyl group is located above the hydantoin ring (dimeric motif D13, Figure 7), which

\section{(a)}

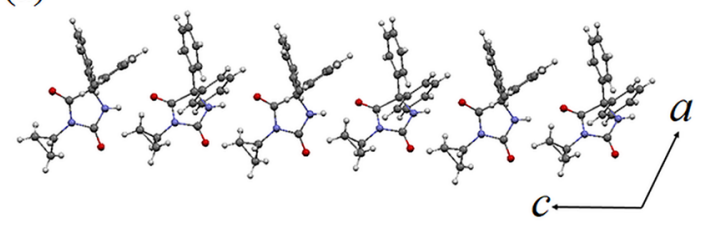

(b)

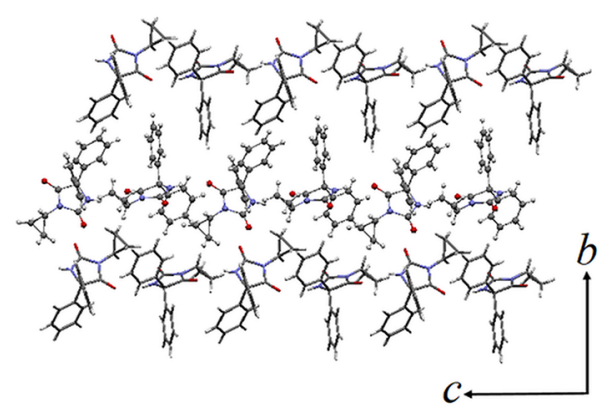

(c)

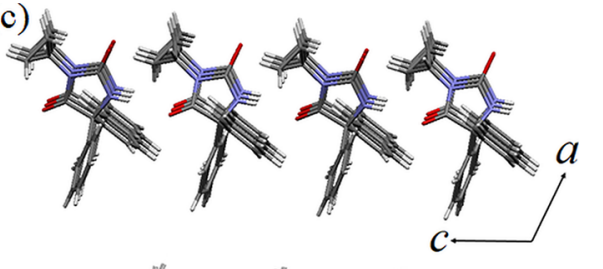

(d)

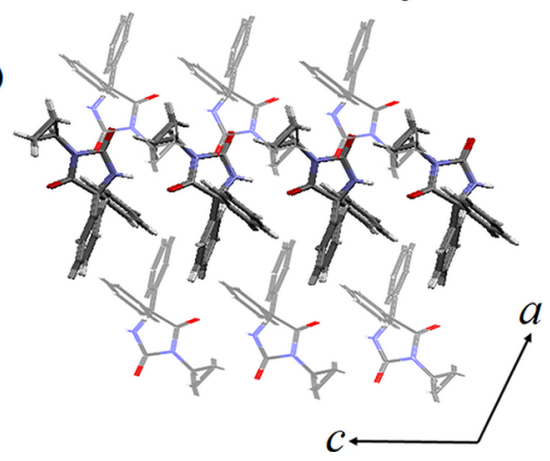

Figure 10. Crystal packing of compound 3. 

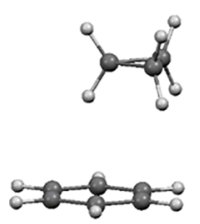

$-3.49 \mathrm{kcal} / \mathrm{mol}$
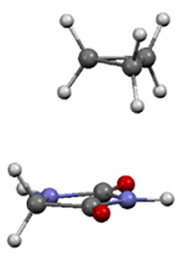

$-3.32 \mathrm{kcal} / \mathrm{mol}$

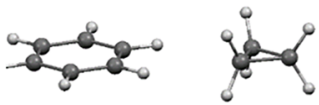

$-1.85 \mathrm{kcal} / \mathrm{mol}$
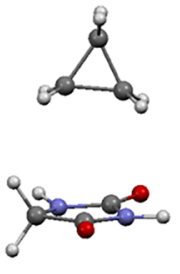

$-4.00 \mathrm{kcal} / \mathrm{mol}$

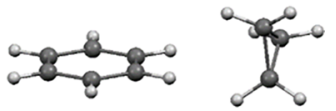

$-2.22 \mathrm{kcal} / \mathrm{mol}$

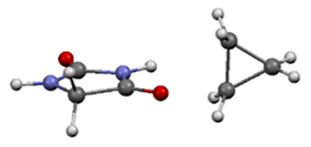

$-4.48 \mathrm{kcal} / \mathrm{mol}$

Figure 11. Optimized orientations of the cyclopropane/benzene and cyclopropane/hydantoin model systems and the corresponding interaction energies (in $\mathrm{kcal} / \mathrm{mol}$ ).

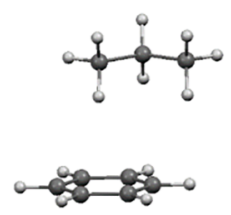

$-3.31 \mathrm{kcal} / \mathrm{mol}$
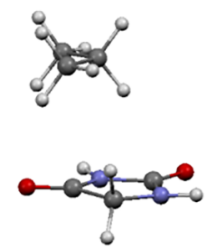

$-3.99 \mathrm{kcal} / \mathrm{mol}$

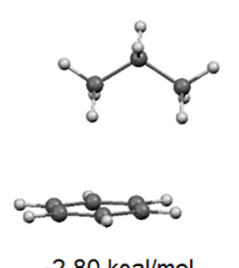

$-2.80 \mathrm{kcal} / \mathrm{mol}$
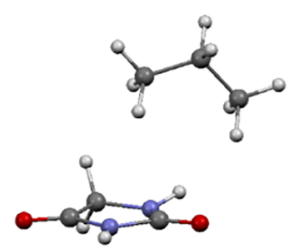

$-3.60 \mathrm{kcal} / \mathrm{mol}$

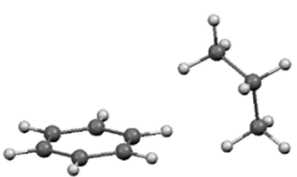

$-1.73 \mathrm{kcal} / \mathrm{mol}$

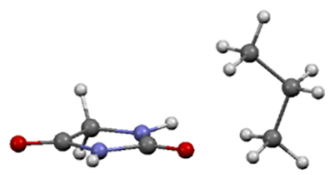

$-3.04 \mathrm{kcal} / \mathrm{mol}$

Figure 12. Optimized orientations of the propane/benzene and propane/hydantoin model systems, and the corresponding interaction energies (in $\mathrm{kcal} / \mathrm{mol}$ ).
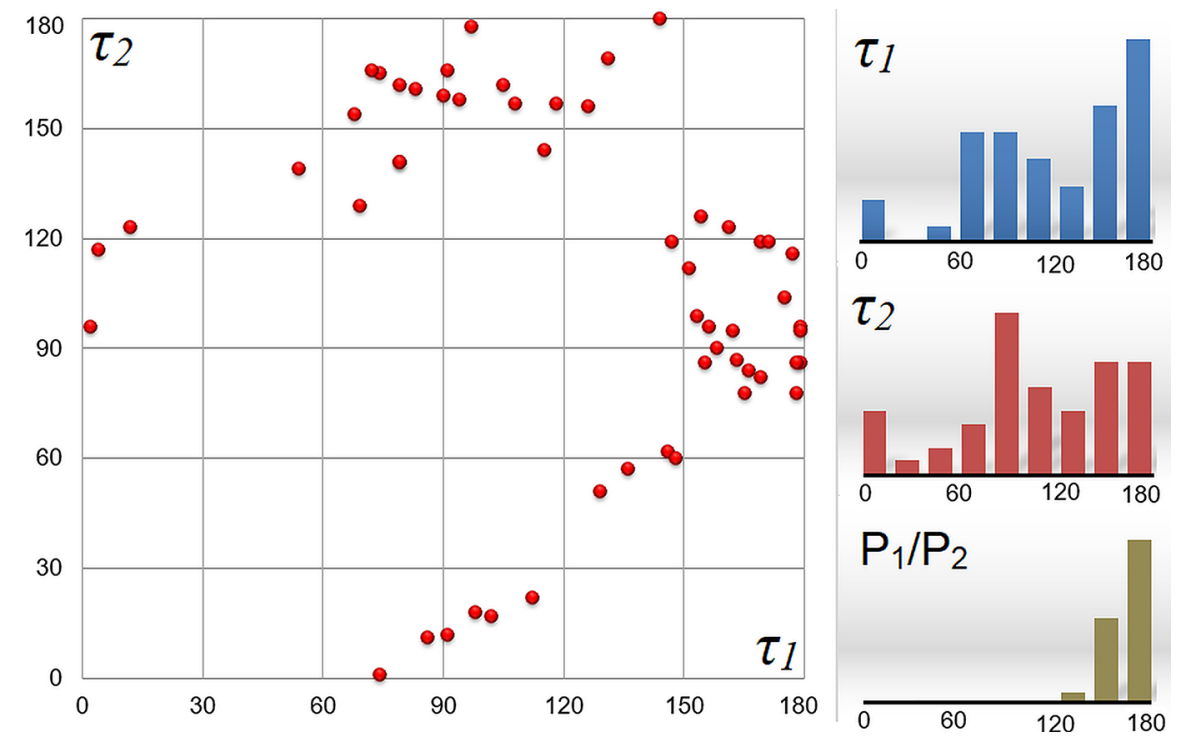

Figure 13. Distributions of the geometric parameters describing the mutual orientation of the phenyl and hydantoin rings $\left(\mathrm{P}_{1} / \mathrm{P}_{2}\right.$ parameter, $\tau_{1}$ and $\tau_{2}$ torsion angles) in the crystal structures of coordinated phenytoins in position $\mathrm{N} 3$.

is probably a consequence of a stronger interaction between the phenyl group and the hydantoin ring, in comparison to interaction between the propyl group and the hydantoin ring.
The interaction energy for the optimized structure for the benzene-hydantoin dimer, with benzene positioned above the hydantoin ring, is $-7.28 \mathrm{kcal} / \mathrm{mol}$ (Figure S6). 
It is known that the benzene molecules tend to build parallel interactions at a large offset $(4.0-6.0 \AA)$ in the crystal structures rather than the stable stacking interactions (offset of $1.5 \AA$ ). ${ }^{40}$ These interactions between benzene molecules at the large offset values are substantially attractive (around $2.0 \mathrm{kcal} / \mathrm{mol}$ ) and offer better possibilities of a dense packing. It is interesting that the contribution of parallel interactions at the large offset values between two benzene molecules in dimeric motif D12 $(-1.46$ $\mathrm{kcal} / \mathrm{mol}$, Figure S7) is greater than the $\mathrm{C}-\mathrm{H} \cdots \mathrm{O}$ interaction of benzene with the hydantoin $\mathrm{C}=\mathrm{O}$ group $(-1.31 \mathrm{kcal} / \mathrm{mol}$, Figure S7).

Impact of Phenytoin Coordination on the Phenyl Groups Orientation and the Stability of the Phenytoin Compounds. By analyzing the crystal structures extracted from the CSD, it was observed that the structures with coordinated hydantoin are more numerous (55 structures). In the case of metal complexes with the 5,5-diphenylhydantoinate (phenytoinate) ligand (Figure 13), there is a clear tendency of the phenyl rings to orient outside the hydantoin ring $\left(\tau_{1}\right.$ and $\tau_{2}$ angles greater than $100^{\circ}$ ), or close to the $\mathrm{N} 1-\mathrm{H}$ group $\left(\tau_{1}\right.$ and $\tau_{2}$ have values close to $\left.100^{\circ}\right)$. This tendency is a consequence of voluminous substituents in position $\mathrm{N} 3$, which prevent the phenyl groups to position above the hydantoin ring (illustration is shown at Figure S8, structure with refcode VELZOC). ${ }^{41}$

The results of the calculation of the model system of hydantoin complex, extracted from the crystal structure with refcode IPOYUI (Figure S9), ${ }^{29}$ showed that the coordination of phenytoin through $\mathrm{N} 3$ atom to $\mathrm{Ni}(\mathrm{II})$ leads to a greater rotational freedom of the phenyl groups. Namely, the difference between the most stable and most unstable structure is less than $90 \mathrm{kcal} / \mathrm{mol}$ (Table 5), in comparison to noncoordinated

Table 5. Relative Energies (in $\mathrm{kcal} / \mathrm{mol}$ ) for Coordinated Compound (Calculated with Respect to the Most Unstable Orientation of the Phenyl Rings) as the Function of Values of the Torsion Angles $\tau_{1}$ and $\tau_{2}{ }^{a}$

\begin{tabular}{cccccccc}
\hline$\tau_{1} \downarrow \tau_{2} \rightarrow$ & $0^{\circ}$ & $30^{\circ}$ & $60^{\circ}$ & $90^{\circ}$ & $120^{\circ}$ & $150^{\circ}$ & $180^{\circ}$ \\
\hline $0^{\circ}$ & -76.8 & -75.5 & -82.2 & -85.1 & -84.3 & -81.4 & -76.8 \\
$30^{\circ}$ & -75.5 & -40.9 & -63.6 & -83.5 & $-\mathbf{8 5 . 5}$ & -82.8 & -75.5 \\
$60^{\circ}$ & -81.3 & -62.6 & $\mathbf{0 . 0}$ & -68.4 & -84.4 & -83.8 & -81.3 \\
$90^{\circ}$ & -83.9 & -82.3 & -68.2 & -60.7 & -82.6 & -84.2 & -83.9 \\
$120^{\circ}$ & -83.1 & -84.3 & -84.2 & -82.6 & -84.0 & -83.4 & -83.1 \\
$150^{\circ}$ & -80.7 & -82.0 & -84.0 & -84.6 & -83.7 & -81.4 & -80.7 \\
$180^{\circ}$ & -76.8 & -75.5 & -82.2 & -85.1 & -84.3 & -81.4 & -76.8 \\
\hline
\end{tabular}

${ }^{a}$ The orientations with energies up to $10 \mathrm{kcal} / \mathrm{mol}$ less than the most stable orientation are marked with the dark gray background; the orientations with energies from 10 to $20 \mathrm{kcal} / \mathrm{mol}$ less than the most stable orientation are marked with the light gray background; the least stable orientations are marked with the white background.

phenytoin derivatives, where this difference is much higher and amounts to approximately $135 \mathrm{kcal} / \mathrm{mol}$ (Table 3 ) supported by a larger number of orientations with energy for $10 \mathrm{kcal} / \mathrm{mol}$ less than the most stable orientation $\left(\tau_{1}=30^{\circ}\right.$ and $\left.\tau_{2}=120^{\circ}\right)$.

Docking Study. The docking study revealed 50 most stable orientations of the investigated compounds inside the voltagegated ion channel in the open and closed state. Although slightly differing in the conformation, all docked molecules are bound to the same binding site (forming a cluster, Figures 14 and S10) with binding energies ranging from -7.3 to $-7.5 \mathrm{kcal} / \mathrm{mol}$ (Table 6) when the channel is in the open state. In this way, these molecules block the transport of ions through the channel.
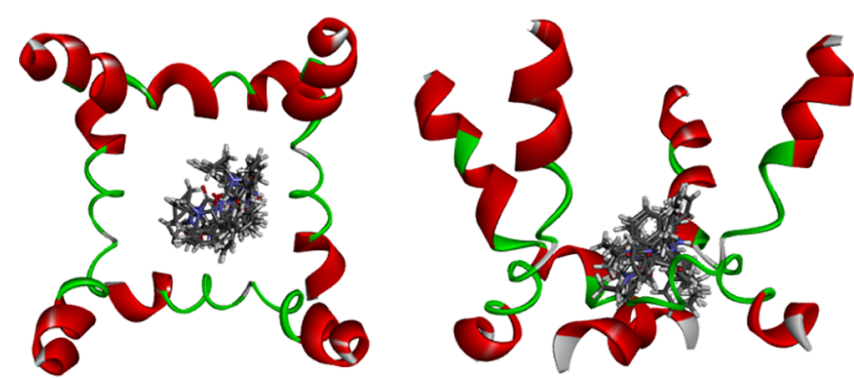

Figure 14. Cluster binding site of the investigated compounds in the voltage-gated ion channel in the open state.

Table 6. Binding Energies (in $\mathrm{kcal} / \mathrm{mol}$ ) for the Most Stable Orientation of the Investigated Compounds and VoltageGated Ion Channel in the Open and Closed States

\begin{tabular}{ccc} 
compound & open state & closed state \\
\hline $\mathbf{1}$ & -7.5 & -8.6 \\
$\mathbf{2}$ & -7.5 & -8.8 \\
$\mathbf{3}$ & -7.3 & -9.1 \\
$\mathbf{4}$ & -7.3 & -9.0 \\
$\mathbf{5}$ & -7.3 & -9.1 \\
\hline
\end{tabular}

The results also showed that differences in the length and branching of the substituent $\mathrm{R}$ do not have an important role in binding to the pump (Figures S11-S15). Namely, the alkyl substituents mainly form hydrophobic interactions with amino acids from the environment (with ValF:87, LeuF:88, LeuG:88, PheF:91, and LysD:7) in the binding sites with the highest binding energies. The orientation of the phenyl groups is usually determined by $\mathrm{C}-\mathrm{H} \cdots \pi$ interaction (with LysD:7, ValF:87, ValH:87, AlaC:7) and $\pi \cdots \pi$ aromatic interactions (with $\mathrm{PheH}: 84$, PheF:91). The hydantoin ring is involved in the interactions with the amino acid residues only in systems with compounds $4(\mathrm{O}-\mathrm{H} \cdots \mathrm{O}$ hydrogen bond with ThrG:87) and 5 $(\mathrm{N}-\mathrm{H} \cdots \pi$ interactions with $\mathrm{PheH}: 84$ and $\mathrm{C}-\mathrm{H} \cdots \mathrm{O}$ interaction with ThrG:87).

In the closed state of the pump, the inner helices form the $\mathrm{K}^{+}$ ion selectivity filter region (Figure S16) under which a cavity exists. Docking calculations showed that all docked molecules also form a cluster inside the voltage-gated ion channel (Figure $15)$, with the binding energies from -8.6 to $-9.1 \mathrm{kcal} / \mathrm{mol}$ (Table 6). By binding within the channel, these molecules prevent the normal function of the pump, thus making the change from the closed to open state difficult. All compounds in
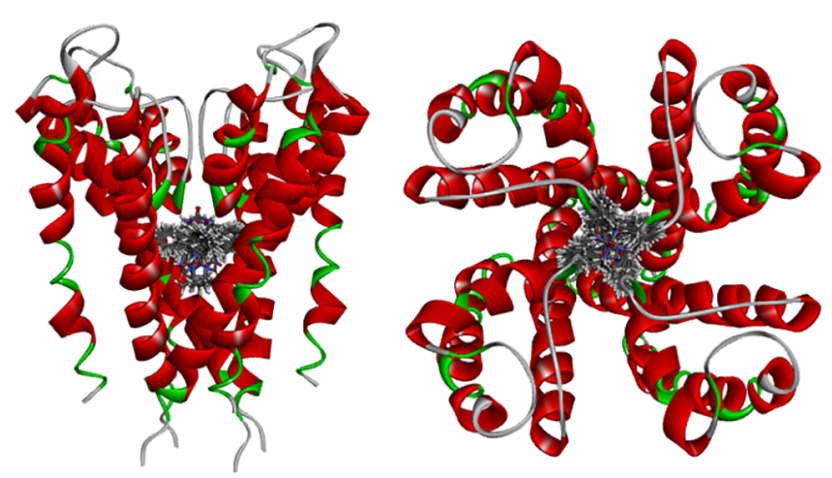

Figure 15. Cluster binding site of the investigated compounds in the voltage-gated ionic channel in the closed state. 
the most stable orientation form at least two hydrogen bonds as acceptors through the carbonyl $\mathrm{O}$ atom of the hydantoin ring (interacting with ThrA:75, ThrB:75, or ThrC:75), while compounds 1 and $\mathbf{2}$ additionally form hydrogen bonds as donors through the $\mathrm{N} 1-\mathrm{H}$ group of the hydantoin ring (interacting with ThrA:75 and ThrD:75) (Figures S17-S21). The substituent $\mathrm{R}$ forms hydrophobic interactions, usually with IleB:100, IleC:100, or PheA:103, while the phenyl groups simultaneously form $\mathrm{C}-\mathrm{H} \cdots \pi$ interactions with IleA:100 and IleDS: 100 .

\section{CONCLUSIONS}

The investigated series underlines a fine distinction in the crystal structures of phenytoin derivatives as a result of the variation in the length and branching of the substituent in position N3 of the hydantoin ring. Regarding the conformational preferences of the investigated compounds, the obtained results indicated that the relative orientations of the rings correspond to the most stable calculated geometries, and the selected substituents do not have significant influence on them. However, substituent effects are reflected in different patterns of intermolecular interactions established with species in their environment. With the exception of compound 3, the crystal structure of the investigated compounds contain centrosymmetric dimers linked by paired $\mathrm{N}-\mathrm{H} \cdots \mathrm{O}$ hydrogen bonds; these supramolecular motifs are connected by the pairs of $\mathrm{C}-\mathrm{H} \cdots \mathrm{O}$ interactions and the parallel interaction of two phenyl rings at a large offset to generate chains running along the $c$-axis. Compound 3 containing the cyclopropyl group forms the chain linked by one $\mathrm{N}-\mathrm{H} \cdots \mathrm{O}$ hydrogen bond, one $\mathrm{C}-\mathrm{H} \cdots \mathrm{O}$ interaction, and two $\mathrm{C}-\mathrm{H} \cdots \pi$ interactions. The observed differences are confirmed by different contribution of intermolecular interactions involving the alkyl (i.e., propyl) and cyclopropyl groups. Furthermore, results of crystallographic analysis and quantumchemical calculations revealed that metal ion coordination of phenytoin allows more rotational freedom for the phenyl groups, so phenytoin can adopt the desired conformation with less energetic penalty comparing to noncoordinated derivatives. Docking calculations for two states of the voltage-gated ion channel showed that the investigated compounds inhibit the pump and preferentially stabilize the closed state. In this case, the hydantoin ring is involved mainly in hydrogen bonding with the threonine side chains. Interestingly, hydrogen bonds involving the carbonyl groups seem to be preferred over those formed by the $\mathrm{N}-\mathrm{H}$ groups. The substituent $\mathrm{R}$ forms hydrophobic interactions, while the phenyl groups are further stabilized through the $\mathrm{C}-\mathrm{H} \cdots \pi$ and $\pi \cdots \pi$ interactions with either isoleucines or phenylalanines.

We believe that the applied integrated approach can provide an insight into the importance of individual structural fragments of phenytoin derivatives in their stability as well as their supramolecular structures, and may lead to a design of new compounds with improved pharmaceutical properties.

\section{ASSOCIATED CONTENT}

\section{S Supporting Information}

The Supporting Information is available free of charge on the ACS Publications website at DOI: 10.1021/acs.cgd.8b01776.

Table S1 with selected geometrical parameters of compounds $\mathbf{1 - 5}$, Figure S1 presenting the crystal structure of ethyl (2,5-dioxo-4,4-diphenylimidazolidin-1yl)acetate (refcode JALGEL), ${ }^{38}$ Figures S2-S5 showing dimeric motifs identified in the crystal packing of the investigated compounds, Figure S6 describing the optimized orientation of the benzene/hydantoin dimer, Figures S7 showing the structures of benzene/benzene and benzene/hydantoin dimers, with geometries taken from the dimeric motif D12, Figure S8 providing the crystal structure of bis(5,5-diphenylhydantoinato-kN3)bis $\left(1 \mathrm{H}\right.$-imidazole-kN ${ }^{3}$ ) copper(II) complex (refcode VELZOC), ${ }^{41}$ Figure S9 representing the crystal structure of tetra-aqua-(bis(2,5-dioxo-4,4-diphenylimidazolidin-1yl))-nickel(II) (refcode IPOYUI), ${ }^{29}$ Figure S10 showing the Lipkind model of the voltage-gated ion channel in the open state, Figure S16 showing the structural model of the voltage-gated ion channel in the closed state, and Figures S11-S15 and S17-S21 illustrating docking into the voltage-gated ion channels in the open and closed states (PDF)

\section{Accession Codes}

CCDC 1880607-1880611 contain the supplementary crystallographic data for this paper. These data can be obtained free of charge via www.ccdc.cam.ac.uk/data_request/cif, or by emailing data_request@ccdc.cam.ac.uk, or by contacting The Cambridge Crystallographic Data Centre, 12 Union Road, Cambridge CB2 1EZ, UK; fax: +44 1223336033.

\section{AUTHOR INFORMATION}

\section{Corresponding Author}

* Tel: +381 113303 869. Fax: +381 113370 387. E-mail: ntrisovic@tmf.bg.ac.rs.

ORCID 우

Nemanja Trišović: 0000-0002-9231-4810

Lidija Radovanović: 0000-0002-7505-6290

\section{Author Contributions}

The manuscript was written through contributions of all authors. All authors have given approval to the final version of the manuscript.

\section{Notes}

The authors declare no competing financial interest.

\section{ACKNOWLEDGMENTS}

This work was supported by the Ministry of Education, Science and Technological Development of the Republic of Serbia (Projects no. 172013, III45007, and 172023).

\section{REFERENCES}

(1) Isaacson, E. I. Central nervous system depressants. In Wilson and Gisvold's Textbook of Organic Medicinal and Pharmaceutical Chemistry; Bloch, J. H., Beale, J. M., Eds.; Lippincott Williams and Wilkins: Baltimore, 2004; p 505.

(2) Wang, L. W.; Subbiah, R. N.; Kilborn, M. J.; Dunn, R. F. Phenytoin: an old but effective antiarrhythmic agent for the suppression of ventricular tachycardia. Med. J. Aust. 2013, 199, 209-211.

(3) Rizzon, P.; Di Biase, M.; Favale, S.; Visani, L. Class 1B agents lidocaine, mexiletine, tocainide, phenytoin. Eur. Heart J. 1987, 8, 2125.

(4) Pereira, C. A. Z.; de Oliveira de A Alchorne, A. Assessment of the effect of phenytoin on cutaneous healing from excision of melanocytic nevi on the face and on the back. BMC Dermatol. 2010, 10, 7.

(5) Namazi, M. R. Phenytoin as a novel anti- vitiligo weapon. J. Autoimmune Dis. 2005, 2, 11.

(6) Nokhodchi, A.; Bolourtchian, N.; Dinarvand, R. Crystal modification of phenytoin using different solvents and crystallization conditions. Int. J. Pharm. 2003, 250, 85-97. 
(7) Codding, P. W.; Duke, N. E.; Aha, L. J.; Palmer, L. Y.; McClurg, D. K.; Szkaradzinska, M. B. Structural and computational studies of anticonvulsants: a search for correlation between molecular systematics and activity. In Crystallographic and Modeling Methods in Molecular Design; Bugg, C. E., Ealick, S. E.; Eds; Springer: New York, 1990.

(8) Jones, G. P.; Andrews, P. R. Structure- activity relations and receptor modelling of convulsant and anticonvulsant barbiturates from crystallographic data. J. Chem. Soc., Perkin Trans. 2 1987, 415-421.

(9) Camerman, A.; Camerman, N. Diphenylhydantoin and diazepam: molecular structure similarities and steric basis of anticonvulsant activity. Science 1970, 168, 1457-1458.

(10) Brown, M. L.; Brown, G. B.; Brouillette, W. J. Effects of log P and phenyl ring conformation on the binding of 5- phenylhydantoins to the voltage- dependent sodium channel. J. Med. Chem. 1997, 40, 602.

(11) Yaari, Y.; Selzer, M. E.; Pincus, J. H. Phenytoin: mechanisms of its anticonvulsant action. Ann. Neurol. 1986, 20, 171-184.

(12) Cook, A. M.; Bensalem-Owen, M. K. Therapy 2011, 8, 307-313.

(13) de Lera Ruiz, M.; Kraus, R. L. Voltage- gated sodium channels: structure, function, pharmacology, and clinical indications. J. Med. Chem. 2015, 58, 7093-7118.

(14) Catterall, W. A. Structure and function of voltage- gated sodium channels at atomic resolution. Exp. Physiol. 2014, 99, 35-51.

(15) Dudley, S. C., Jr.; Chang, N.; Hall, J.; Lipkind, G.; Fozzard, H. A.; French, R. J. $\mu$ - conotoxin GIIIA interactions with the voltage- gated $\mathrm{Na}$ + channel predict a clockwise arrangement of the domains. J. Gen. Physiol. 2000, 116, 679-689.

(16) Lipkind, G. M.; Fozzard, H. A. Molecular model of anticonvulsant drug binding to the voltage- gated sodium channel inner pore. Mol. Pharmacol. 2010, 78, 631-638.

(17) Brown, M. L.; Zha, C. C.; Van Dyke, C. C.; Brown, G. B.; Brouillette, W. J. Comparative molecular field analysis of hydantoin binding to the neuronal voltage- dependent sodium channel. J. Med. Chem. 1999, 42, 1537-1545.

(18) Kanyonyo, M.; Govaerts, S. J.; Hermans, E.; Poupaert, J. H.; Lambert, D. M. 3- Alkyl- (5, 5'- diphenyl) imidazolidinediones as new cannabinoid receptor ligands. Bioorg. Med. Chem. Lett. 1999, 9, 22332236.

(19) Ooms, F.; Wouters, J.; Oscari, O.; Happaerts, T.; Bouchard, G.; Carrupt, P.-A.; Testa, B.; Lambert, D. M. Exploration of the pharmacophore of 3- alkyl- 5- arylimidazolidinediones as new $\mathrm{CB}(1)$ cannabinoid receptor ligands and potential antagonists: synthesis, lipophilicity, affinity, and molecular modeling. J. Med. Chem. 2002, 45, $1748-1756$

(20) Suzuki, H.; Kneller, M. B.; Rock, D. A.; Jones, J. P.; Trager, W. F.; Rettie, A. E. Active- site characteristics of CYP2C19 and CYP2C9 probed with hydantoin and barbiturate inhibitors. Arch. Biochem. Biophys. 2004, 429, 1-15.

(21) Muccioli, G. G.; Fazio, N.; Scriba, G. K. E.; Poppitz, W.; Cannata, F.; Poupaert, J. H.; Wouters, J.; Lambert, D. M. Substituted 2- thioxo- 4imidazolidinones and imidazolidine- 2, 4- diones as fatty acid amide hydrolase inhibitors templates. J. Med. Chem. 2006, 49, 417-425.

(22) Groom, C. R.; Bruno, I. J.; Lightfoot, M. P.; Ward, S. C. The Cambridge structural database. Acta Crystallogr., Sect. B: Struct. Sci., Cryst. Eng. Mater. 2016, 72, 171-179.

(23) Muccioli, G. G.; Poupaert, J. H.; Wouters, J.; Norberg, B.; Poppitz, W.; Scriba, G. K. E.; Lambert, D. M. A rapid and efficient microwave- assisted synthesis of hydantoins and thiohydantoins. Tetrahedron 2003, 59, 1301-1307.

(24) Trišović, N.; Valentić, N.; Ušcumlić, G. Solvent effects on the structure- property relationship of anticonvulsant hydantoin derivatives: a solvatochromic analysis. Chem. Cent. J. 2011, 5, 62.

(25) Burla, M. C.; Caliandro, R.; Carrozzini, B.; Cascarano, G. L.; Cuocci, C.; Giacovazzo, C.; Mallamo, M.; Mazzone, A.; Polidori, G. Crystal structure determination and refinement via SIR2014. J. Appl. Crystallogr. 2015, 48, 306-309.

(26) Sheldrick, G. M. Crystal structure refinement with SHELXL. Acta Crystallogr., Sect. C: Struct. Chem. 2015, C71, 3-8.

(27) Farrugia, L. J. WinGX and ORTEP for Windows: an update. J. Appl. Crystallogr. 2012, 45, 849-854.
(28) Frisch, M. J.; Trucks, G. W.; Schlegel, H. B.; Scuseria, G. E.; Robb, M. A.; Cheeseman, J. R.; Scalmani, G.; Barone, V.; Mennucci, B.; Petersson, G. A.; Nakatsuji, H.; Caricato, M.; Li, X.; Hratchian, H. P.; Izmaylov, A. F.; Bloino, J.; Zheng, G.; Sonnenberg, J. L.; Hada, M.; Ehara, M.; Toyota, K.; Fukuda, R.; Hasegawa, J.; Ishida, M.; Nakajima, T.; Honda, Y.; Kitao, O.; Nakai, H.; Vreven, T.; Montgomery, J. A., Jr.; Peralta, J. E.; Ogliaro, F.; Bearpark, M.; Heyd, J. J.; Brothers, E.; Kudin, K. N.; Staroverov, V. N.; Kobayashi, R.; Normand, J.; Raghavachari, K.; Rendell, A.; Burant, J. C.; Iyengar, S. S.; Tomasi, J.; Cossi, M.; Rega, N.; Millam, N. J.; Klene, M.; Knox, E. J.; Cross, J. B; Bakken, V.; Adamo, C.; Jaramillo, J.; Gomperts, R.; Stratmann, R. E.; Yazyev, O.; Austin, A. J.; Cammi, R.; Pomelli, C.; Ochterski, J. W.; Martin, R. L.; Morokuma, K.; Zakrzewski, V. G.; Voth, G. A.; Salvador, P.; Dannenberg, J. J.; Dapprich, S.; Daniels, A. D.; Farkas, Ö.; Foresman, J. B.; Ortiz, J. V.; Cioslowski, J.; Fox, D. J. Gaussian09; Gaussian, Inc.: Wallingford, CT, 2009.

(29) Puszynska-Tuszkanow, M.; Daszkiewicz, G.; Maciejewska Adach, A.; Cieslak-Golonka, M. Interaction of hydantoins with transition metal ions: Synthesis, structural, spectroscopic, thermal and magnetic properties of $\left[\mathrm{M}\left(\mathrm{H}_{2} \mathrm{O}\right)_{4}(\text { phenytoinate })_{2}\right] \mathrm{M}=\mathrm{Ni}(\mathrm{II})$, Co(II). Struct. Chem. 2010, 21, 315-321.

(30) Doyle, D. A.; Morais Cabral, J.; Pfuetzner, R. A.; Kuo, A.; Gulbis, J. M.; Cohen, S. L.; Chait, B. T.; MacKinnon, R. The structure of the potassium channel: molecular basis of $\mathrm{K}+$ conduction and selectivity. Science 1998, 280, 69-77.

(31) Morris, G. M.; Huey, R.; Lindstrom, W.; Sanner, M. F.; Belew, R. K.; Goodsell, D. S.; Olson, A. J. AutoDock4 and AutoDockTools4: Automated docking with selective receptor flexibility. J. Comput. Chem. 2009, 30, 2785-2791.

(32) Jha, S.; Silversides, J. D.; Boyle, R. W.; Archibald, S. J. Hydrogen bonded dimers vs. one- dimensional chains in 2- thiooxoimidazolidin4- one (thiohydantoin) drug derivatives. CrystEngComm 2010, 12, $1730-1739$.

(33) Graus, S.; Casabona, D.; Uriel, S.; Cativiela, C.; Serrano, J. L. Supramolecular arrangements based on cyclohexane- 5- spirohydantoin derivatives. CrystEngComm 2010, 12, 3132-3137.

(34) Chattopadhyay, B.; Mukherjee, A. K.; Narendra, N.; Hemantha, H. P.; Sureshbabu, V. V.; Helliwell, M.; Mukherjee, M. Supramolecular architectures in 5, 5' - substituted hydantoins: crystal structures and hirshfeld surface analyses. Cryst. Growth Des. 2010, 10, 4476-4484.

(35) Todorov, P. T.; Petrova, R. N.; Naydenova, E. D.; Shivachev, B. L. Structure, conformation and hydrogen bonding of two aminocycloalkanespiro- 5- hydantoins. Cent. Eur. J. Chem. 2009, 7, 14-19.

(36) Lazić, A.; Trišović, N.; Radovanović, L.; Rogan, J.; Poleti, D.; Vitnik, Ž.; Vitnik, V.; Ušcumlić, G. Towards understanding intermolecular interactions in hydantoin derivatives: the case of cycloalkane- 5- spirohydantoins tethered with a halogenated benzyl moiety. CrystEngComm 2017, 19, 469-483.

(37) Luchian, R.; Vinteler, E.; Chis, C.; Vasilescu, M.; Leopold, N.; Chis, V. Molecular structure of phenytoin: NMR, UV- Vis and quantum chemical calculations. Croat. Chem. Acta 2015, 88, 511-522.

(38) Mague, J. T.; Abdel-Aziz, A. A.-M.; El-Azab, A. S. 3-Amino-5,5diphenylimidazolidine-2,4-dione. Acta Crystallogr., Sect. E: Struct. Rep. Online 2014, 70, o262-o263.

(39) Ramli, Y.; Akrad, R.; Guerrab, W.; Taoufik, J.; Ansar, M.; Mague, J. T. Ethyl 2-(2,5-dioxo-4,4-diphenylimidazolidin-1-yl)acetate. IUCrData 2017, 2, 171693.

(40) Ninković, D. B.; Janjić, G. V.; Veljković, D. Ž.; Sredojević, D. N.; Zarić, S. D. What are the preferred horizontal displacements in parallel aromatic-aromatic interactions? Significant interactions at large displacements. ChemPhysChem 2011, 12, 3511-3514.

(41) Xu, X.-Y.; Xu, T.-T.; Ma, H.-P.; Hu, X.-L.; Wang, D. -Q. Bis(5,5diphenylhydantoinato-[kappa]N3)bis(1H-imidazole-[kappa]N3)copper(II) monohydrate. Acta Crystallogr., Sect. E: Struct. Rep. Online 2006, 62, m1956-m1957. 